Portland State University

PDXScholar

Master of Environmental Management Project

Reports

Environmental Science and Management

$12-2020$

\title{
Neighborhood Air Quality Impact from Construction Site Emissions in Portland, OR
}

Lyndsey Boyle

Portland State University

Follow this and additional works at: https://pdxscholar.library.pdx.edu/mem_gradprojects

Part of the Environmental Sciences Commons

Let us know how access to this document benefits you.

\section{Recommended Citation}

Boyle, Lyndsey, "Neighborhood Air Quality Impact from Construction Site Emissions in Portland, OR" (2020). Master of Environmental Management Project Reports. 62.

https://pdxscholar.library.pdx.edu/mem_gradprojects/62

https://doi.org/10.15760/mem.65

This Project is brought to you for free and open access. It has been accepted for inclusion in Master of Environmental Management Project Reports by an authorized administrator of PDXScholar. Please contact us if we can make this document more accessible: pdxscholar@pdx.edu. 


\section{Neighborhood Air Quality Impact from Construction Site Emissions in Portland, OR}

Lyndsey Boyle

Portland State University

Environmental Science and Management (ESM)

Master's in Environmental Management

Sustainable Atmospheric Research (STAR) Lab

\section{PSI}

\section{STAR LAB}

\section{Committee Members:}

Dr. Linda George, Portland State University ESM

Mary Peveto, Neighbors for Clean Air

Dr. Meenakshi Rao, Portland State University ESM 
Table of Contents

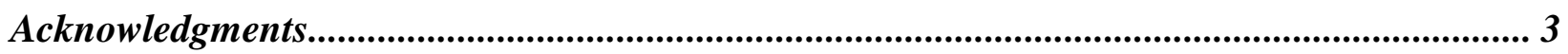

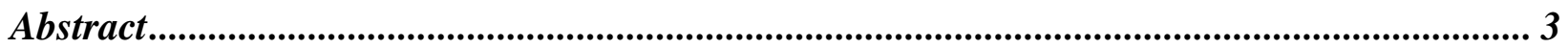

Section I: Introduction to Diesel Pollution ............................................................................. 4

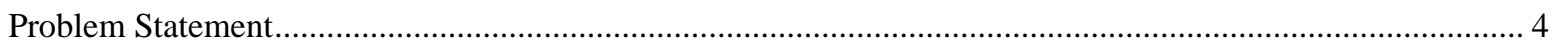

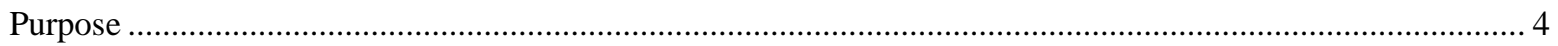

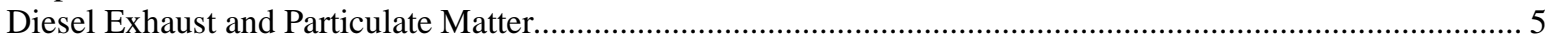

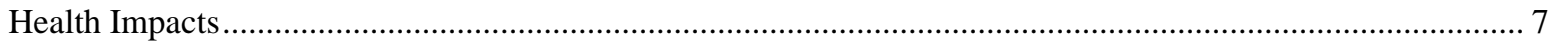

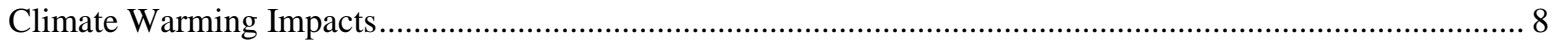

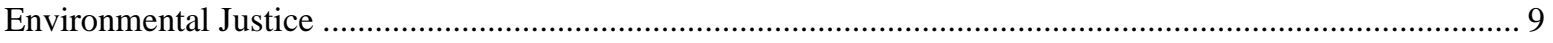

Section II: Diesel Pollution in Oregon.............................................................................. 11

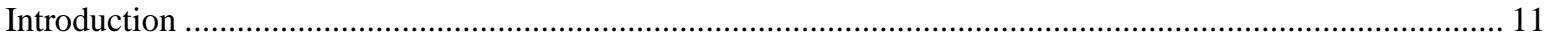

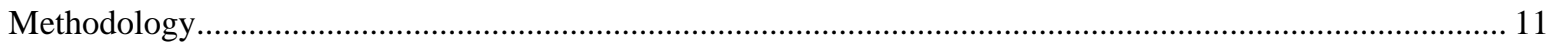

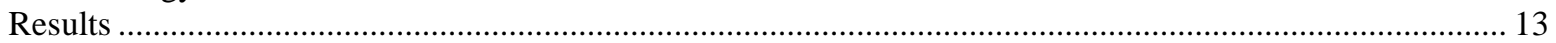

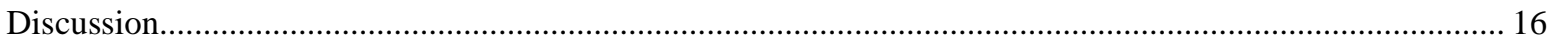

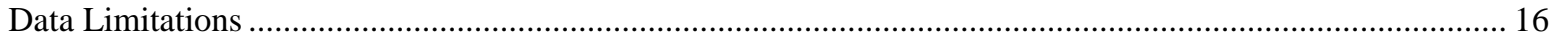

Section III: Construction Site Impact and Presence ....................................................................... 17

Literature Review of Construction-Related Emissions .............................................................................17

Construction Site Presence in Portland, OR: Spatial Analysis .....................................................18

Section IV: Neighborhood Construction Mapping Project ............................................................. 22

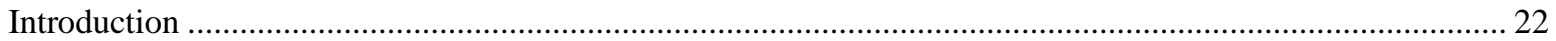

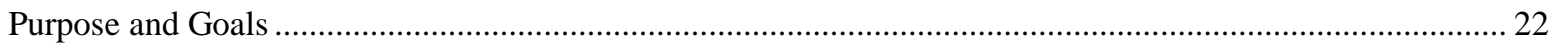

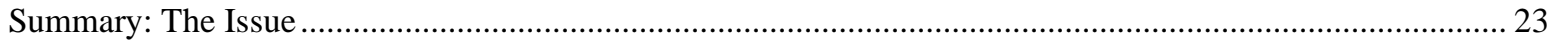

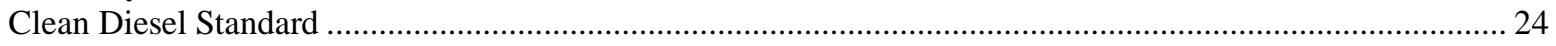

The Mapping Tool ................................................................................................................................27

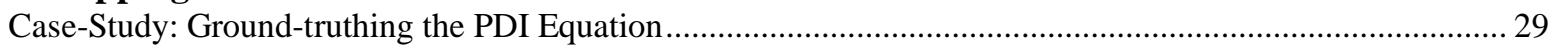

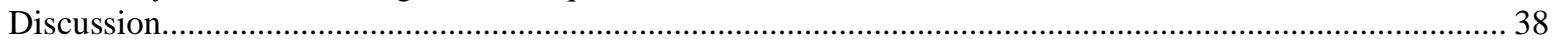

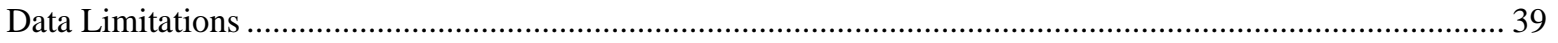

Section V. Conclusions \& Recommendations........................................................................ 40

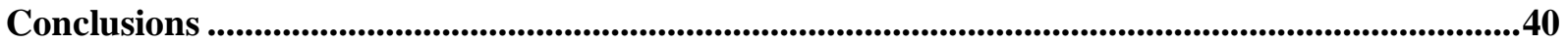

Recommendations .......................................................................................................................................41

Areas of Future Research ..........................................................................................................................42

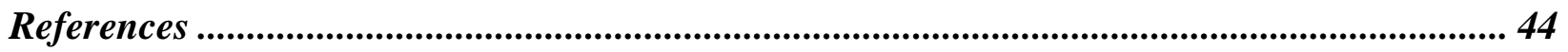

Appendix A: EPA Engine Class Definitions....................................................................... 48

Appendix B: Additional Figures for Spatial Analysis of Construction Sites ............................. 49

Appendix C. "The Issue” webpage contents................................................................................. 52

Appendix D: Portland SE Lafayette Monitoring Station Data ......................................................5 57

Appendix E: Citizen Science Tool Framework................................................................................. 58 


\section{Acknowledgments}

I would like to thank my graduate advisor, Dr. Linda George. She encouraged me to keep going further into this research, which ultimately resulted in a large body of work that I am proud to have been a part of. I really appreciated her perspective as an atmospheric chemist who also deeply cares about effecting change. I would also like to thank my community partner, Mary Peveto, from Neighbors for Clean Air. She has supported me from the first time we met and is one of the most innovative, persistent, and well-spoken individuals I have ever met. I aspire to be more like her in my career. Dr. Meenakshi Rao, my final committee member, was also incredibly helpful in determining the best way to go about presenting my results and making sure that I interpret them into applicable conclusions and recommendations.

The Mapping Action Collective team and Randy Morris were also instrumental in getting the whatsinourair.org website created. This project would be nowhere near as effective or tangible without their hard work.

I would also like to thank my fellow PSU ESM graduate students, especially those in my lab. It has been such a pleasure to learn from and with them. I would not have had nearly as much fun without them.

And last but not least, I would like to thank my partner, Cassidy. He has been the biggest support to me through this entire journey.

\section{Abstract}

Research has shown that diesel particulate matter, including black carbon, is harmful to human health and has climate warming properties. Emissions from off-road engines, specifically construction, are a major source of diesel particulate matter in Portland, OR. There has been little done to manage the impact that construction has on local air quality. This project included a review of recent literature on the health and climate warming effects of particulate matter and black carbon, a modeling study to better understand what the major sources of diesel particulate matter are in Oregon, and a review of current research on construction site emissions. This study also included field monitoring of black carbon at construction sites in Portland, OR which showed that local air quality can be affected. The information gathered in this project, and in partnership with Neighbors for Clean Air, informed content for an interactive web page to help educate and motivate local residents to better understand what's in their air. This study revealed that there are many opportunities to leverage existing policies and increase incentives for construction projects to adopt cleaner technology and reduce emissions on site. 


\section{Section I: Introduction to Diesel Pollution}

\section{Problem Statement}

Diesel Particulate Matter (DPM) is any solid particle emitted from a diesel engine during combustion and can contain multiple types of chemicals and metals (Betts, 2011). It is not the only pollutant that comes from the tailpipe, but it is one of the most harmful to human health. The particles are often small enough to travel into your lungs and into your bloodstream, which impacts both the respiratory and endocrine system (Ntziachristos et. al., 2007).

The age of the diesel engine tends to correlate with the amount of emissions that will come out of the tailpipe (USEPA, 2016). Diesel engines are incredibly durable, which enables them to last for much longer than a gasoline engine and are used predominately to power heavy, non-road equipment such as agricultural, forestry, and construction equipment. These sectors are often relying on older equipment with higher emission rates due to having little incentives to upgrade. According to the EPA, a new diesel engine made in 2019 emits 98\% less than one from 1970.

Currently only 6 air pollutants are federally regulated, leaving more than 180 hazardous air toxics in a grey area which have both adverse environmental and human health effects. Even these 6 pollutants that are regulated are only measured as ambient concentrations at select monitoring locations. However, local air quality may not be the same everywhere because diesel pollution can impact micro-environments and vary greatly in an urban environment (George et. al., 2019). Local concentrations of DPM have been difficult to estimate in Oregon because only on-road passenger vehicles are required to be emission tested in urban areas, which leaves larger sources of diesel particulate matter like off-road equipment and heavy-duty trucks to operate without reporting emissions. In urban areas like Portland, this is a serious concern because it is adding to the already elevated levels of air pollution due to high traffic. Construction equipment is believed to be the biggest source of Diesel PM in Portland (ODEQ, 2012).

Diesel exhaust has been shown to be harmful for both human health and for the environment, which will be detailed further in this section.

\section{Purpose}

This project intends to illustrate the impact that diesel exhaust, in general and specifically from construction equipment, has on Portland's air and its residents and possible solutions to mitigate this. Construction equipment in Portland and statewide tends to be older than the national average, increasing the interest in understanding the impact and supporting the case for better regulation of these engines (ODEQ, 2020). This project, therefore, working in partnership with Neighbors for Clean Air, aims to gather information for the development of an interactive 
website for the general public to understand how diesel exhaust from construction impacts their neighborhood air quality.

To achieve this, this project includes understanding the impacts from diesel exhaust, modeling diesel emissions in Oregon, on-the-ground measurements of diesel pollution near construction sites in Portland and modeling potential diesel pollution reduction from stricter regulations in the city. This information was used to inform the new website for Neighbors for Clean Air, whatsinourair.org.

\section{Diesel Exhaust and Particulate Matter}

Diesel engines can be stationary (e.g. diesel generators) but are most often mobile and can include both on-road sources (e.g. heavy-duty trucks, buses) and non-road sources (locomotives, construction equipment, marine vessels). Diesel exhaust can include both particles as well as gases, such as NOx, SO2, and NH3. While these gases can have health and environmental impacts, this project will focus on particulate matter because of their unique impact to human health and climate warming. Diesel Particulate Matter (DPM) refers to the portion of diesel exhaust that are particles, meaning anything that is solid.

Research has shown that many different components can be included in DPM, such as elemental carbon, metals, organic carbon, sulfate, and nitrate, but elemental carbon is the primary component. The ratio can vary greatly depending on equipment type, age, and fuel composition, but Figure 1.1 shows that elemental carbon typically makes up about $75 \%$ of Diesel Exhaust Particulate, also known as DPM (Long et. al., 2013). Because of this, this project has chosen to focus on elemental carbon specifically when talking about DPM because it can act as a proxy for DPM.

\section{(c) "Traditional" Diesel Exhaust Particulate (DEP)}

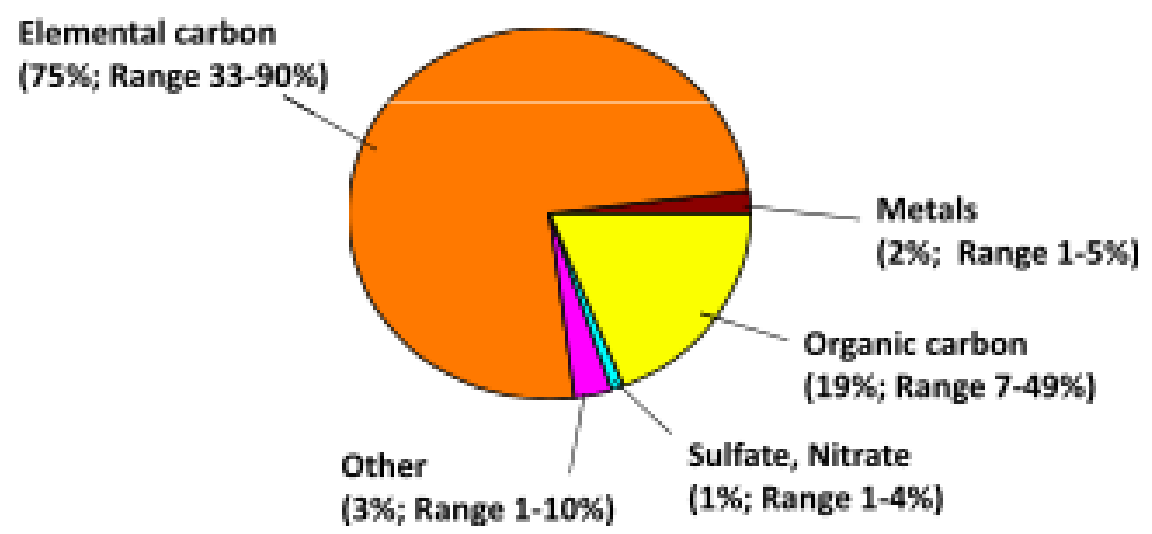

Figure 1.1. Average make-up of traditional diesel exhaust particulate, also known as Diesel PM. Source: Long et. al., 2013. 
Focusing on elemental carbon is also strategic because particulate matter in an urban area can come from a variety of sources, not just diesel engines, whereas most of the elemental carbon in an urban area comes from diesel-fueled sources. One study found that diesel-fueled sources contribute only about $16.8 \%$ of urban particulate matter compared to that of $77.9 \%$ of elemental carbon in urban cities (Diaz-Robles et. al., 2008). Elemental carbon is used as an ambient DPM tracer in many studies because of this.

Within elemental carbon, this project has chosen to focus on black carbon. Much of the elemental carbon in Diesel PM is black carbon, however it is helpful to be specific because they are not completely synonymous. Black carbon is typically defined similarly to soot and is black or brown substance formed as a result of incomplete combustion of fossil fuels (see Table 1.1). Brown carbon on the other hand is similar but is the elemental carbon that is not technically soot, but still has light-absorbing physical properties. Unlike black carbon, brown carbon is usually a result of burning plant material, organic compounds in soils, or VOCs from vegetation. They share some similar effects but come from different sources and there has been more effort recently to keep these terms separated (Andreae \& Galenscer, 2006).

Table 1.1. A definition of key terms to characterize elemental carbon and various forms of it. (Source: Andreae \& Galenscer, 2006).

\begin{tabular}{|l|l|}
\hline Term & Definition \\
\hline Black Carbon & $\begin{array}{l}\text { Elemental carbon with light-absorbing } \\
\text { properties. Similar to Soot carbon. }\end{array}$ \\
\hline Brown Carbon & $\begin{array}{l}\text { Light-absorbing organic matter (other than } \\
\text { Soot Carbon). Origins typically include soil } \\
\text { humics, humic-like substances, bioaerosols, } \\
\text { biomass combustion. }\end{array}$ \\
\hline Elemental Carbon & $\begin{array}{l}\text { Near-elemental soot-carbon like composition. } \\
\text { Fraction of carbon that is oxidized in } \\
\text { combustion analysis above a temperature } \\
\text { threshold. }\end{array}$ \\
\hline Soot & $\begin{array}{l}\text { A black or brown substance formed by } \\
\text { combustion, present as fine particles. }\end{array}$ \\
\hline Soot Carbon & $\begin{array}{l}\text { Carbon particles with the morphological and } \\
\text { chemical properties typical of soot particles } \\
\text { from combustion. }\end{array}$ \\
\hline
\end{tabular}

Black carbon is not yet completely understood and has only been studied for a few decades. One of the earliest studies summarizing black carbon was published in 1985 (Goldberg). However, 
with more research of black carbon being done, more concern has been present at the policy level in recent years. The EPA published a Report to Congress on Black Carbon in 2012 which summarized scientific research that has shown black carbon's contribution to adverse human health outcomes as well as climate warming effects. There is still not a formal chemical definition of black carbon, but research has been done on chemical and physical properties of the particles (Long, 2013).

\section{Health Impacts}

Particulate matter (PM) can enter the body of varying sizes, ranging from about 10 micrometers (coarse) to about 0.018 micrometers (ultrafine). The larger particles are better filtered out naturally by the body through the nasal chamber and digestive tract and do not typically reach the lungs or bloodstream. Currently there are federal standards for ambient concentrations of PM10 and PM2.5, where PM10 denotes all particles 10 micrometers or less and PM2.5 denotes 2.5 micrometers or less in size (US EPA, 2020). Figure 1.2 shows the relative size of PM10 and PM2.5. However, the concern is that much of the particulate matter that comes from diesel engines is often the finest component of PM2.5 and is described as fine, ultrafine, and nanoparticles, which travel deep into the body and is of most concern (Diaz-Robles, 2008). PM2.5 is responsible for $63 \%$ of deaths from environmental causes in the United States, making it the leading environmental health risk factor (Tessum et. al., 2019).

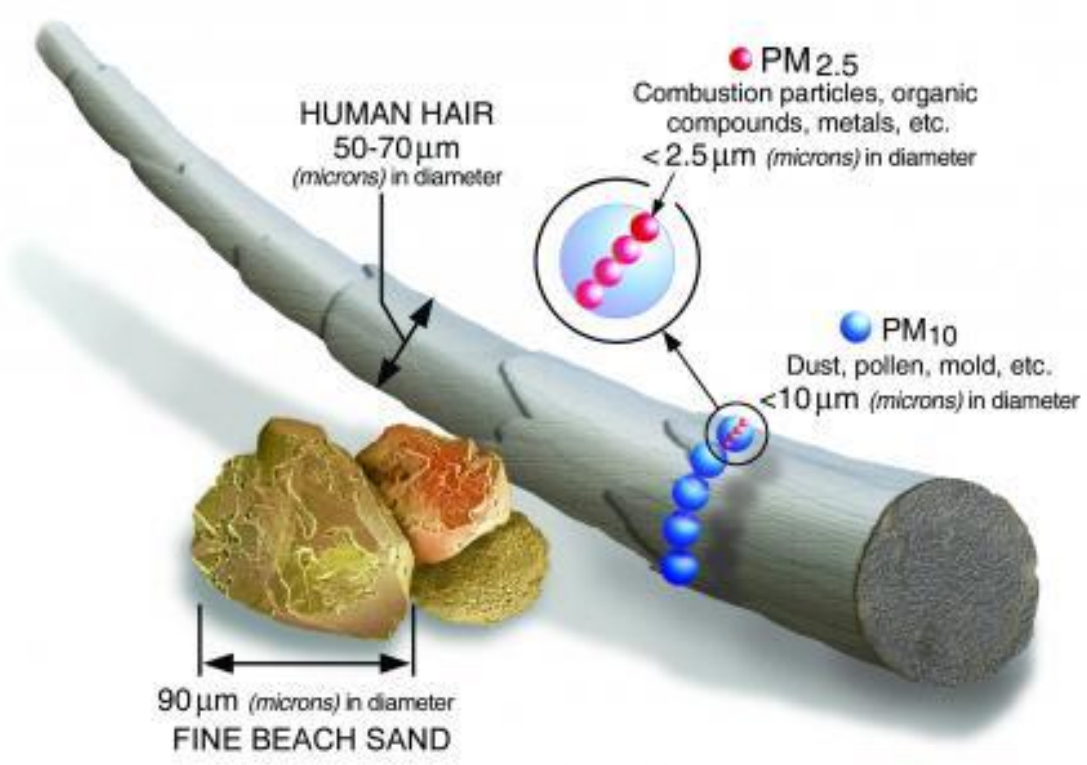

Figure 1.2. This image depicts the size of PM2.5 and PM10 compared to human hair and fine beach sand. Ultrafine particles are even smaller than PM2.5 and can range all the way down to 0.018 microns (Source: US EPA, 2020). 
The size distribution of particles from these ultrafine particles (defined as those 0.18 micrometers or less in size) is concerning because an increasing amount of literature shows increased toxicity compared to larger particles on a per mass basis (Donaldson, 2000). A study done near a freeway with high heavy-duty diesel truck traffic showed an elevated level of all PM2.5 compared to background concentrations with the particle-size breakdown, which suggests that traffic is a major source of fine and ultrafine particles in an urban environment (Ntziachristos et. al., 2007).

In June 2012, the World Health Organization's International Agency for Research on Cancer (IARC) updated its rankings, shifting diesel exhaust from a probable to a known carcinogen. Diesel exhaust poses a cancer risk that is 7.5 times higher than the combined cancer risk from all other air toxics in the nation (Diaz-Robles, 2008). Another study found that $70 \%$ of total cancer risk related to air toxics is found to be attributable to Diesel Particulate Matter (CARB, 2018). This is especially an issue in urban environments where air pollution is already of concern, which explains why diesel exhaust has become a major issue in air emissions regulation and policy.

In addition to cancer risk, these small particles also impact the respiratory system causing conditions like asthma and lung disease. Studies have shown that air pollution, specifically from diesel exhaust, can cause inflammation of the airway walls (Alexis \& Carlsten, 2014). Epidemiologic reports have also shown that among people who live near major highways and roadways experience a higher prevalence of asthma and allergy-type symptoms (Salam et. al., 2008).

These risks are even greater for children and can be impacted pre-pregnancy. Children with exposure to a high level of diesel exhaust particles where associated with physician-diagnosed rhinitis and seasonal allergic rhinitis (Codispoti et. al., 2008). Even offspring with pre-pregnancy (before a person is pregnant) exposure to diesel exhaust particles were predisposed to asthma and increased airway inflammation and hyperresponsiveness, as well as during pregnancy (Gorska et. al., 2015).

These small particles, specifically PM2.5 and elemental carbon, have also been known to increase the likelihood for cardiovascular issues. Studies have shown there is a correlation between high concentrations of PM and increased numbers of nearby hospital visits for cardiovascular issues. This includes congestive heart failure, heart disease, peripheral vascular and cerebrovascular disease, and cardiovascular morbidity (Metzger et. al., 2004).

\section{Climate Warming Impacts}


Emerging literature has shown that black carbon particles from diesel exhaust are also having detrimental impact to climate warming. Microscopic black carbon particles suspended in air are the second highest contributor to climate change, tied with methane and following closely behind $\mathrm{CO} 2$. While some aerosols have a cooling effect on global temperature, black carbon particles absorb solar radiation, influence cloud processes, and can increase the melting of snow and ice cover due to its physical properties of color and size (Bond et. al., 2013).

Black carbon is somewhat missed when talking about climate warming agents because much of the focus is on greenhouse gases, which typically do not include mentions of particulate matter. However, a recent in-depth review of black carbon states, "Mitigation of diesel-engine sources appears to offer the most confidence in reducing near-term climate forcing" (Bond et. al., 2013). This is because, unlike carbon dioxide and methane, black carbon has a short lifespan in the atmosphere averaging around 2-6 weeks. Carbon Dioxide can take about 70-100 years to leave the atmosphere and methane stays for about 10 years. This short residence time suggests that reducing black carbon emissions today would likely have cooling effects quickly which makes it a rising strategy for combatting climate change.

Although the atmospheric lifetime of black carbon is short, it can travel to remote regions and interfere with cloud formation and precipitation. Black carbon that travels to the arctic or regions with snow and ice can cause decrease the albedo resulting in faster melting (Bond et. al., 2013). This can cause a positive loop effect, meaning the more snow that melts causes warmer temperatures, which will melt more snow and so on.

These climate forcing behaviors that black carbon holds are one of the drivers for awareness building and mitigation techniques happening at the policy level. One example of this is the extensive report from the US EPA gave to Congress on black carbon. In this document, they estimated that transportation emissions are the number one source of black carbon emissions in the United States, contributing 52.3\% of total black carbon in the US in 2005 (US EPA, 2012).

\section{Environmental Justice}

The concept of environmental justice, sometimes called environmental racism, refers to the issue of historically marginalized communities are often living near higher rates of environmental pollution and risk. Spatial analysis has shown that areas with a high rate of poverty and people of color are more likely to live near superfund sites and sources of air pollution (Banzhaf et. al., 2019). This phenomenon only exacerbates the social and economic inequities these communities already face by increasing their likelihood to develop environmental-related health conditions, such as asthma, lung cancer, chronic allergies, and cancer.

A recent study has also shown that these communities are exposed to air pollution that greatly outweigh their consumption of goods and services that contribute to it (Tessum et. al., 2019). This study found that Black and Hispanic people on average bear a pollution burden of 56\% and 
$63 \%$ excess exposure respectively relative to the exposure caused by their consumption in the United States. On the inverse, white populations are exposed to an average of $17 \%$ less air pollution than is caused by their consumption. 


\section{Section II: Diesel Pollution in Oregon}

\section{Introduction}

According to a report by the Oregon Department of Environmental Quality (ODEQ), residents living in the Portland Metropolitan area are exposed to diesel pollution that exceeds the healthbased standards by 10 times (2012). The human health implications and climate warming impacts of this are described in Section I. While a lot of the sources of diesel pollution are from mobile sources, there are emissions from point sources as well.

Cleaner Air Oregon is an initiative led by Oregon Governor Kate Brown which has led to tightened regulations to targeted air pollutants (ODEQ, 2020). Regulations currently only target emissions from point sources and their emissions directly coming from smokestacks. However, this excludes additional emissions from mobile sources that these stationary sources attract and contribute indirectly to air pollution such as trucks, rail, boats, and construction throughout their processes and production.

There is an urgent need to reduce emissions from these mobile sources, given their health and environmental impacts. Schlusser et. al. proposes an indirect source rule to start to decrease emissions from mobile sources in the region. They describe an indirect source rule as "a type of regulation that aims to improve air quality by reducing or restricting aggregate emissions from all mobile sources operating at, or associated with, an indirect source" (2019). This would not mitigate emissions from all mobile sources in the city, however, it would be a start to decreasing emissions from mobile sources in the region ${ }^{1}$.

The following modeling study was conducted to better understand the role of different vehicles in contributing to Oregon's diesel pollution problem. The data found in this study was to inform a petition for regulation over indirect sources, such as warehouse distribution centers and construction sites on behalf of Neighbors for Clean Air (NCA, 2020).

\section{Methodology}

To assess the current level of diesel pollution in Oregon, the EPA MOVES2014b modeling software was used ${ }^{2}$. modeling software estimates emissions from both on-road and off-road vehicles in a specified county or state in the United States. The simplest way to run MOVES2014b is to rely on national default data. Alternatively, customized data can be input

\footnotetext{
${ }^{1}$ The Indirect Source Rule can be found here.

${ }^{2}$ U.S. Environmental Protection Agency. 2014. User Guide for

MOVES2014b. http://www.epa.gov/otaq/models/moves/documents/420b14055.pdf (accessed 2020)
} 
into the model but is often difficult to obtain. For the purpose of this model, national average data was used due to availability.

The MOVES2014b model was run for the following geographic areas: Oregon statewide, Multnomah County, Clackamas County, Washington County, Jackson County, Lane County, and Marion County. The counties were chosen because they are the 6 highest populated counties and make-up half of the state's population collectively (US Census Bureau, 2010).

The emission inventory was done for the year 2014 in order have data that could be easily compared to the most recent data published EPA National Emission Inventory (NEI) database. The NEI data is compiled by EPA every 3 years and is publicly accessible. At the time of the study, 2017 had not yet been published. All on-road and off-road vehicles with Diesel fuel were included in the model. For a full detailed overview of the run specifications of the model, see Table 2.1.

Table 2.1. MOVES2014b Run Specifications Used

\begin{tabular}{|l|l|l|}
\hline & On-Road & Off-Road \\
\hline Aggregation Level & Emission Inventory & Emission Inventory \\
\hline Year & 2014 & 2014 \\
\hline Geographic Area & $\begin{array}{l}\text { Multnomah, Clackamas, } \\
\text { Washington, Marion, Lane, } \\
\text { Jackson counties }\end{array}$ & $\begin{array}{l}\text { Multnomah, Clackamas, } \\
\text { Washington, Marion, Lane, } \\
\text { Jackson counties }\end{array}$ \\
& Oregon statewide & Oregon statewide \\
\hline Time Span & $\begin{array}{l}\text { Annual (all months, days, } \\
\text { hours) }\end{array}$ & $\begin{array}{l}\text { Annual (all months, days, } \\
\text { hours) }\end{array}$ \\
\hline Vehicle Types & All on-road & All off-road \\
\hline Fuel Type & Diesel only & Diesel only \\
\hline Road Type & All road types & All road types \\
\hline Pollutants & PM2.5, NOx, CO2, & PM2.5, NOx, CO2, \\
\hline Output level & Sector, vehicle type & Sector, vehicle type \\
\hline
\end{tabular}

The results were split into the following categories: On-road Diesel Heavy Duty Vehicles, Onroad Diesel Light Duty Vehicles, Off-road Diesel Equipment, Locomotives, and Commercial Marine Vessels. Almost all off-road equipment is heavy duty and is therefore not separated out into weight categories. For full definitions, see Appendix A Table A1.

PM2.5 was the pollutant of interest because MOVES2014b does not include black carbon emissions estimates for off-road vehicles. Most particulate matter that comes from diesel engines is small, so PM2.5 is preferable to PM10. 


\section{Results}

For all 6 counties in this study, off-road diesel equipment and on-road diesel heavy duty vehicles were the top two PM2.5 contributors and had similar levels of emissions. For all counties the total contribution to diesel PM2.5 from these two categories made up over half of total diesel PM2.5. In Washington and Clackamas counties, off-road had higher PM2.5 emissions than onroad heavy duty vehicles, while the rest had the biggest contribution from on-road heavy duty vehicles, see Figure 2.1 for details.

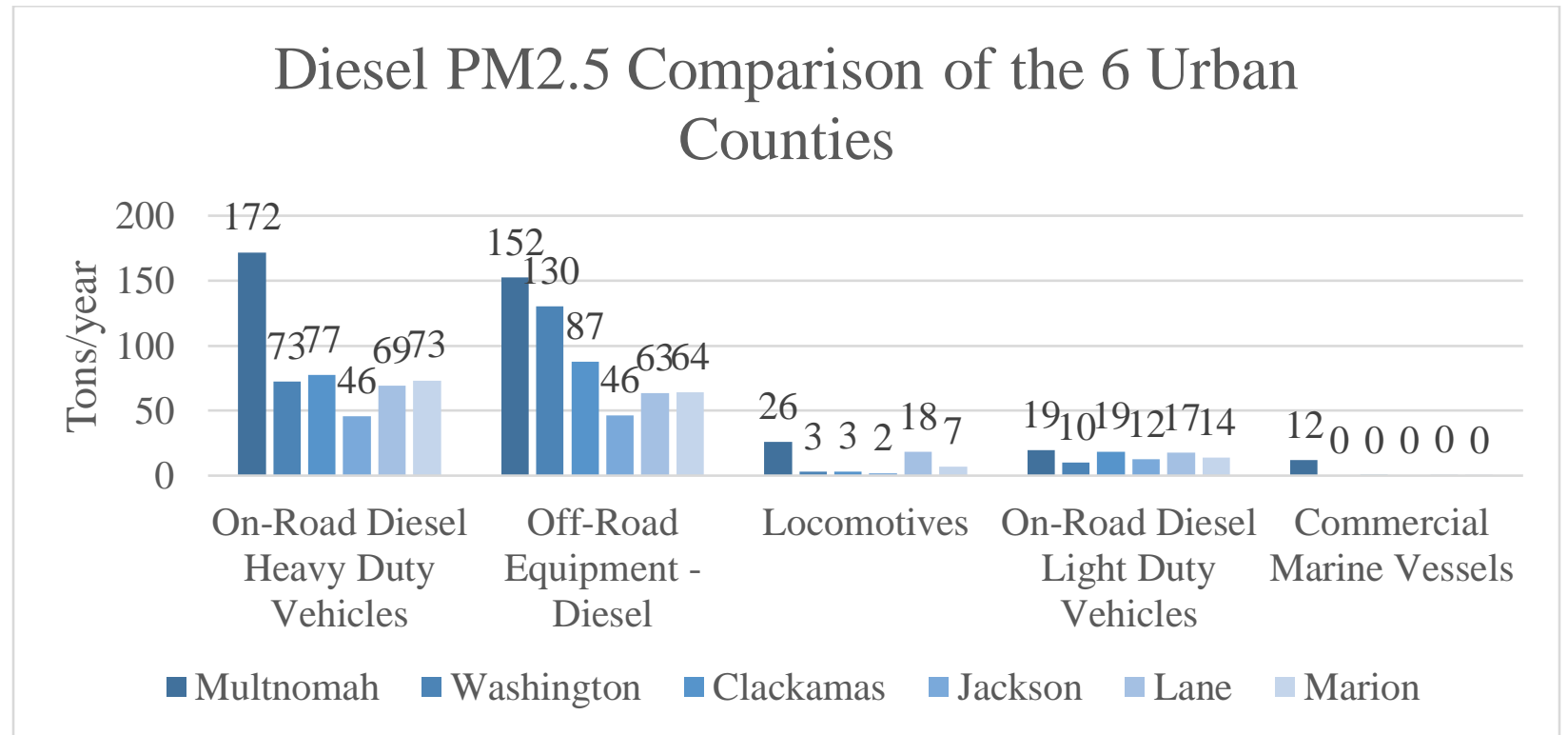

Figure 2.1. Mobile Diesel PM2.5 Emissions for 2014 for the top 6 most populated counties in Oregon (Source: EPA NEI 2014). 


\section{Diesel PM2.5 by Counties in Oregon}

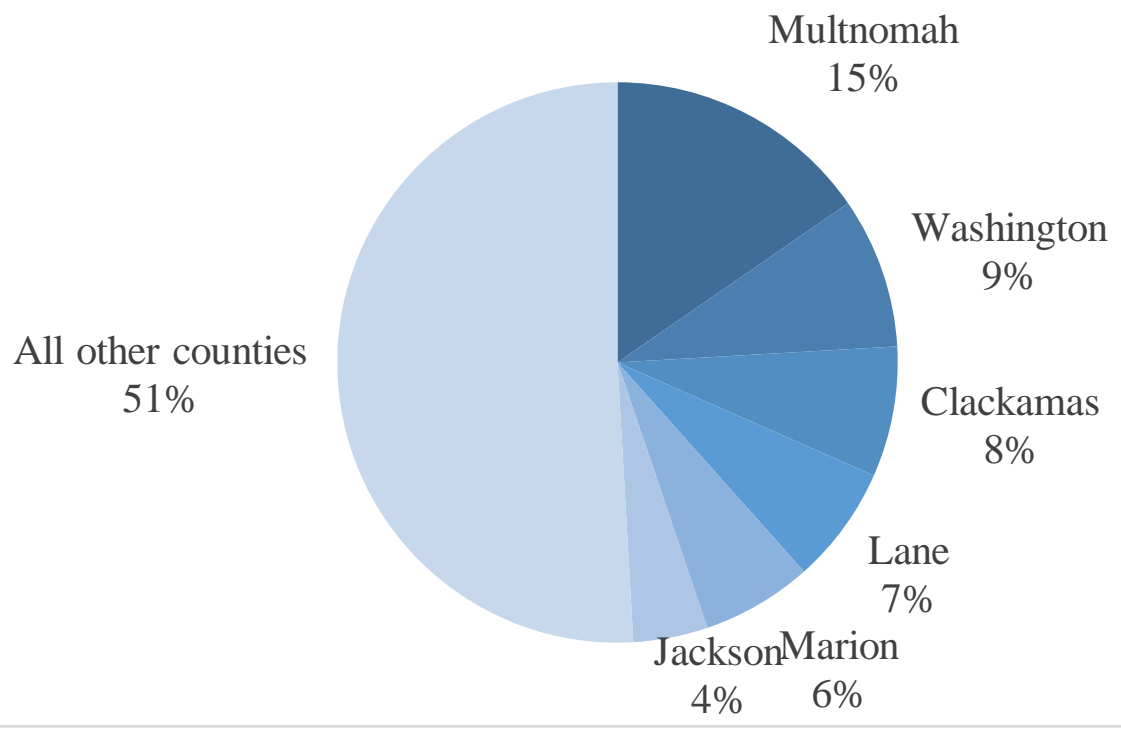

Figure 2.2. The relative contribution to Diesel PM2.5 in Oregon by County (Source: MOVES2014b).

To compare how urban counties differ from rural counties, Oregon statewide emissions were gathered. Diesel PM2.5 does tend to occur at higher levels in areas with higher population, as seen in Figure 2.2. According to the MOVES model, the 6 counties make up about half of the Diesel PM in Oregon as well as about half of the state's population. The Portland Metro area, made up of Multnomah, Washington, and Clackamas counties accounts for about $32 \%$ of the state's Diesel PM.

The on-road heavy duty vehicle category is almost entirely referring to large semi-trucks and buses but the off-road vehicle category includes many different types of equipment. The off-road category includes: construction, agricultural, logging, lawn and garden, airport transport, recreational, commercial, and industrial equipment. For a more detailed list of equipment included in each sector, see Appendix A Table A1. To account for these different sectors, Figures 2.3 and 2.4 show the \% Diesel PM2.5 with the off-road category split into these sector categories.

In both Oregon and the Portland Metro area, off-road heavy duty vehicles is the highest contributing category and construction is the second highest category. The rest of the categories change drastically, where agriculture has a much bigger impact when looking at the state versus when looking in the metro area. This is in line with observations given there is more farmland outside of the metropolitan core.

Construction makes up 30\% of total Diesel PM2.5 in the Portland Metro area and 20\% statewide. In both geographic views, construction is the highest contributing off-road engine source of 
diesel PM, which gives us strong evidence that construction is a sector of significance in tackling the diesel problem in the state.

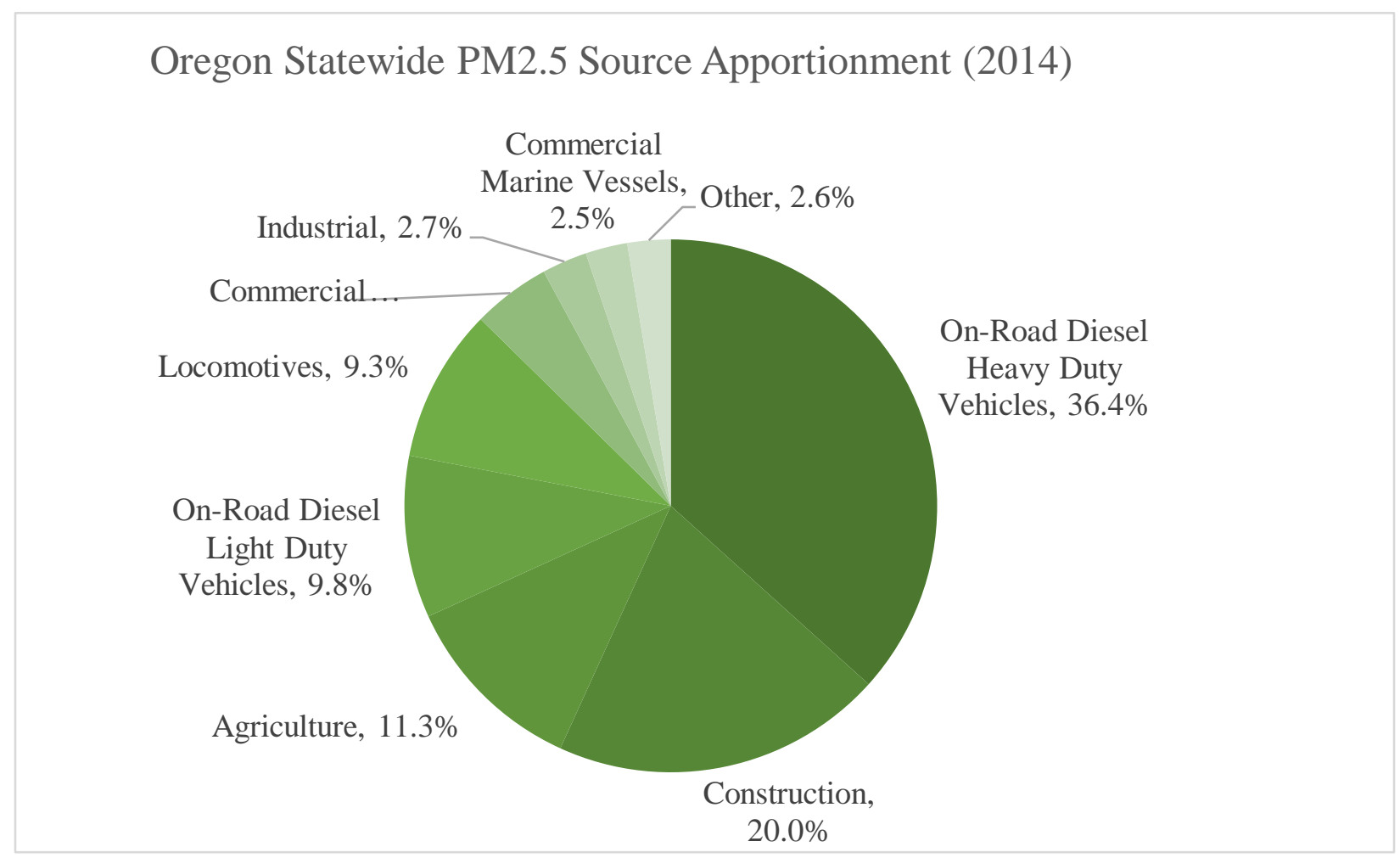

Figure 2.3 Oregon Statewide Diesel PM2.5 Sources by category (Source: MOVES2014b).

\section{Portland Metro Area PM2.5 Source Apportionment}

\section{(2014)}

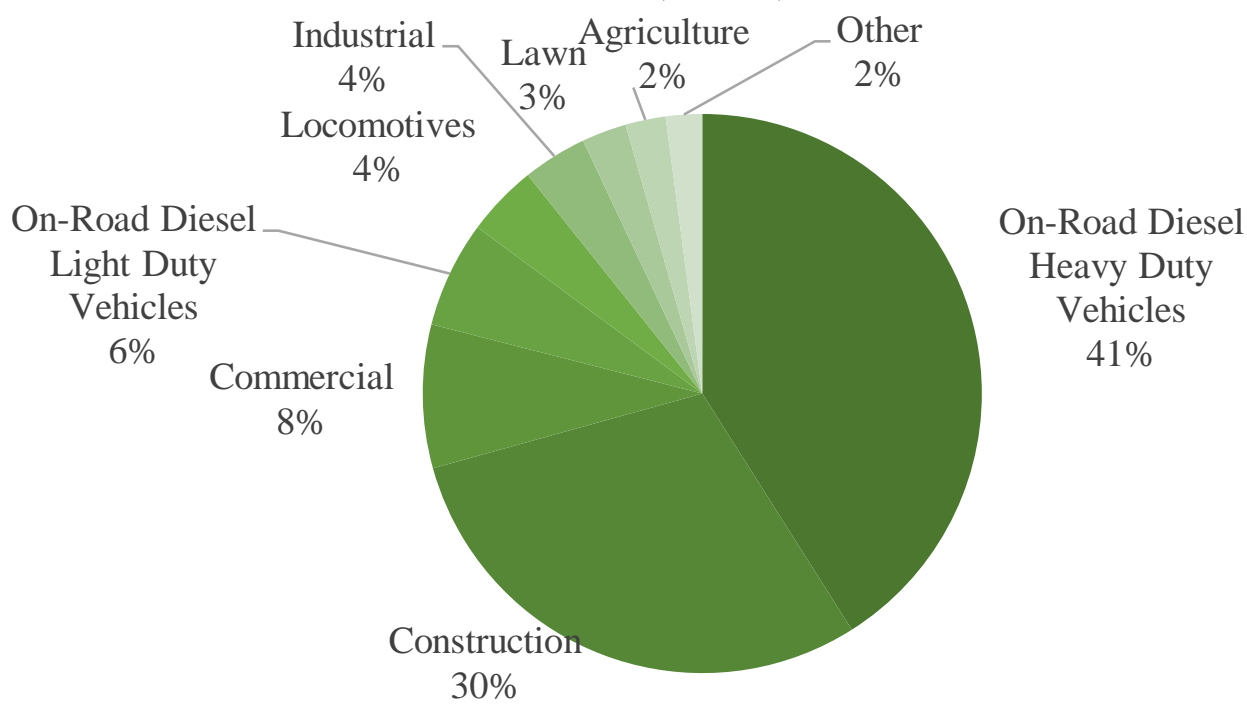

Figure 2.4 Portland Metro Diesel PM2.5 Sources by category. This includes Multnomah, Clackamas, and Washington Counties in Oregon (MOVES2014b). 


\section{Discussion}

The US National Emissions Inventory has shown that the mobile emissions of PM2.5 are significant to the total PM in Oregon, contributing 2.27 times the total PM2.5 that stationary sources do (agricultural and wildfire events excluded). This is evidence to suggest that an indirect source rule could be effective in mitigating PM2.5 emissions in Oregon and locally. When identifying major contributors to diesel PM2.5 emissions in Oregon and the Portland Metro area specifically, the off-road sector as a whole make up the majority, at $54 \%$ and $53 \%$ respectively.

When looking at off-road sectors individually, construction is the driving sector both at a state and Portland metro scale. While it is second to on-road heavy-duty vehicles for total Diesel PM contribution, construction equipment may be easier to regulate at a state and local level. Because much of the heavy-duty vehicles are large trucks, they are often in the shipping and product delivery business and may be trucks originating from all over the country, not necessarily Oregon.

This research among others has motivated Neighbors for Clean Air to become invested creating awareness and advocating for policy solutions to the diesel problem at the state and local level.

\section{Data Limitations}

Due to time and access constraints, this model was developed using EPA's national default data which uses broad regional averages. Because of this, there is some uncertainty with the data and actual observed amounts of diesel PM2.5 in Oregon. Additionally, working with modeled data always lends itself to limitations because actual emissions are variable.

The age and activity rates of the engines are two of the inputs that have the largest impact on output emissions. Unfortunately, most off-road diesel equipment is unregulated and so data on these engines are quite limited across the state. A year after this study was done, DEQ published a off-road diesel equipment study to help better understand these two variables for off-road diesel equipment. In the future, this study can be reproduced using the updated data in the DEQ report (DEQ, 2020). Given the findings in the report, the difference in running the model using national default data and customized Oregon data may not change results dramatically. However, there were some significant differences at the sector level, so it would be worthwhile. 


\section{Section III: Construction Site Impact and Presence}

\section{Literature Review of Construction-Related Emissions}

Among scientific research, there has been little effort to quantify impact of off-road vehicles on air quality despite their large contribution (Zavala et. al., 2017). This section will be a summary of recent studies done on off-road emissions, specifically from construction equipment.

Typical heavy-duty construction equipment includes backhoes, bulldozers, excavators, generators, motor graders, off-road trucks, rubber tire loaders, track loaders, and skid-steer loaders. These 9 equipment types are estimated to contribute around 70\% of total PM10, NOx, and $\mathrm{CO}$ emissions from construction equipment in the United States (Rasdorf et. al., 2010). Backhoes are the highest contributor of PM10 on site with an estimated $15.1 \%$ contribution, followed by skid-steer loaders contributing 13.6\% (see Figure 3.1). Construction sites also attract on-road concrete mixing trucks to pour foundation slabs, but these sources are generally excluded from these studies. Emissions were also measured by different operating modes of the equipment: idling, moving, and scooping/dumping. Moving and bucket operation had a PM emission rate that was more than four times as much as idling (Rasdorf et. al., 2010).

Figure 3.1. This table shows the contribution of emissions from the highest contributing 8 pieces of construction equipment (Table 1 from Rasdorf et. al., 2010).

Table 1. Comparison of Contribution and National Ranking of $\mathrm{NO}_{x}, \mathrm{CO}$, and $\mathrm{PM}_{10}$ for Selected Vehicles and Equipment

\begin{tabular}{|c|c|c|c|c|c|c|}
\hline \multirow[b]{2}{*}{ Vehicle } & \multicolumn{2}{|c|}{$\mathrm{NO}_{\mathrm{x}}$} & \multicolumn{2}{|c|}{$\mathrm{CO}$} & \multicolumn{2}{|c|}{$\mathrm{PM}_{10}$} \\
\hline & $\begin{array}{c}\text { Contribution } \\
\text { (\%) }\end{array}$ & $\begin{array}{c}\text { National } \\
\text { ranking }\end{array}$ & $\begin{array}{c}\text { Contribution } \\
(\%)\end{array}$ & $\begin{array}{l}\text { National } \\
\text { ranking }\end{array}$ & $\begin{array}{c}\text { Contribution } \\
(\%)\end{array}$ & $\begin{array}{l}\text { National } \\
\text { ranking }\end{array}$ \\
\hline Front-end loaders & 14.5 & 1 & 11.5 & 3 & 11.2 & 3 \\
\hline bulldozers/track loaders & 12.5 & 2 & 9.3 & 4 & 9.1 & 4 \\
\hline Excavators & 11.4 & 3 & 7.4 & 5 & 8.6 & 5 \\
\hline Off-highway trucks & 11.0 & 4 & 7.3 & 6 & 6.6 & 6 \\
\hline Backhoes & 9.2 & 5 & 16.0 & 1 & 15.1 & 1 \\
\hline Skid-steer loaders & 6.2 & 6 & 14.5 & 2 & 13.6 & 2 \\
\hline Generators & 4.7 & 7 & 5.1 & 7 & 6.0 & 7 \\
\hline \multirow[t]{2}{*}{ Motor graders } & 2.9 & 12 & 1.7 & 14 & 2.1 & 13 \\
\hline & 72.4 & & 72.8 & & 72.3 & \\
\hline
\end{tabular}

Much of the literature attributes the earthworks phase of a project as being responsible for the majority of emissions. This phase of the project is when heavy-duty diesel equipment is most likely to be present for digging into the ground to level the site and prep for foundation work. One study found that the project could contribute up to 44\% of total PM10 in the area during the earthworks phase and $17 \%$ of total PM10 on average during the entire project timeline (Faber et. al., 2015). Another study found that a construction site increased local PM2.5 by $120 \%$ (Azarmi et. al., 2016). When looking at highway expansion impact on air quality, often times the construction of the project can be overlooked. While construction emissions only occur for a shortened amount of time, they can contribute more than 5 times the amount of PM10 than the additional lanes (Font et. al., 2014). 
One of the concerns posed in this research is how these construction emissions impact on a neighborhood scale. Most published studies occur at the construction site, but one study did find that there were significant air quality impacts as far as 100 meters away from the site and recommended to sample much further away in future studies (Araujo et. al., 2014). This particular Brazilian study also recorded PM2.5 emissions up to $105.8 \mathrm{ug} / \mathrm{m} 3$ at construction sites.

Many of these studies did include recommendations for decreasing emissions from these off-road vehicles, including engine retrofits, replacing older engines, using cleaner fuels, reducing idle time, ensuring proper maintenance of engines, and setting emission standards (Kholod \& Evans, 2016). Even something as simple as wetting construction sites during construction has been shown to decrease particulate matter in the air (Font et. al., 2014). Diesel Particle Filters are another cost-effective method to reduce emissions from construction vehicles, potentially up to $61 \%$ of black carbon (Zavala et. al., 2017). However, there are little incentives for companies to install these filters, so they are not expected to achieve high market penetration. Switching to biodiesel is another possible strategy which can reduce black carbon emissions by $76 \%$ compared to regular diesel but would require significant investment in supporting that fuel source (Zhang et. al., 2015).

There appears to be great opportunity for further research in this sector, specifically for understanding black carbon emissions from off-road diesel engines. Studies are also lacking in impact on air quality away from the construction site, so little is known on how far emissions can travel on average. Another opportunity for studies would be to look at cumulative impacts of diesel pollution from construction sites. Often times in urban environments, there may be more than one construction project occurring at the same time in a given area. Little is known on the impact that multiple sites could have on local air quality.

\section{Construction Site Presence in Portland, OR: Spatial Analysis}

An exploratory analysis was done to look at the occurrence of construction projects happening by neighborhood. There was also interest in comparing this to household demographic trends in each neighborhood that impact one's vulnerability to air pollution related health issues. This was done in Spring 2019, prior to the field-monitoring stage which is documented in Section 4. Using the opensource construction permit dataset from PortlandMaps (January 2018-December 2018), maps were generated to identify the neighborhoods with the most construction projects occurring in them as well as those with the largest density of construction (Figures 3.2 and 3.3). The density was determined by taking the total square footage of all construction projects occurring and dividing that by the square footage of the neighborhood area. 


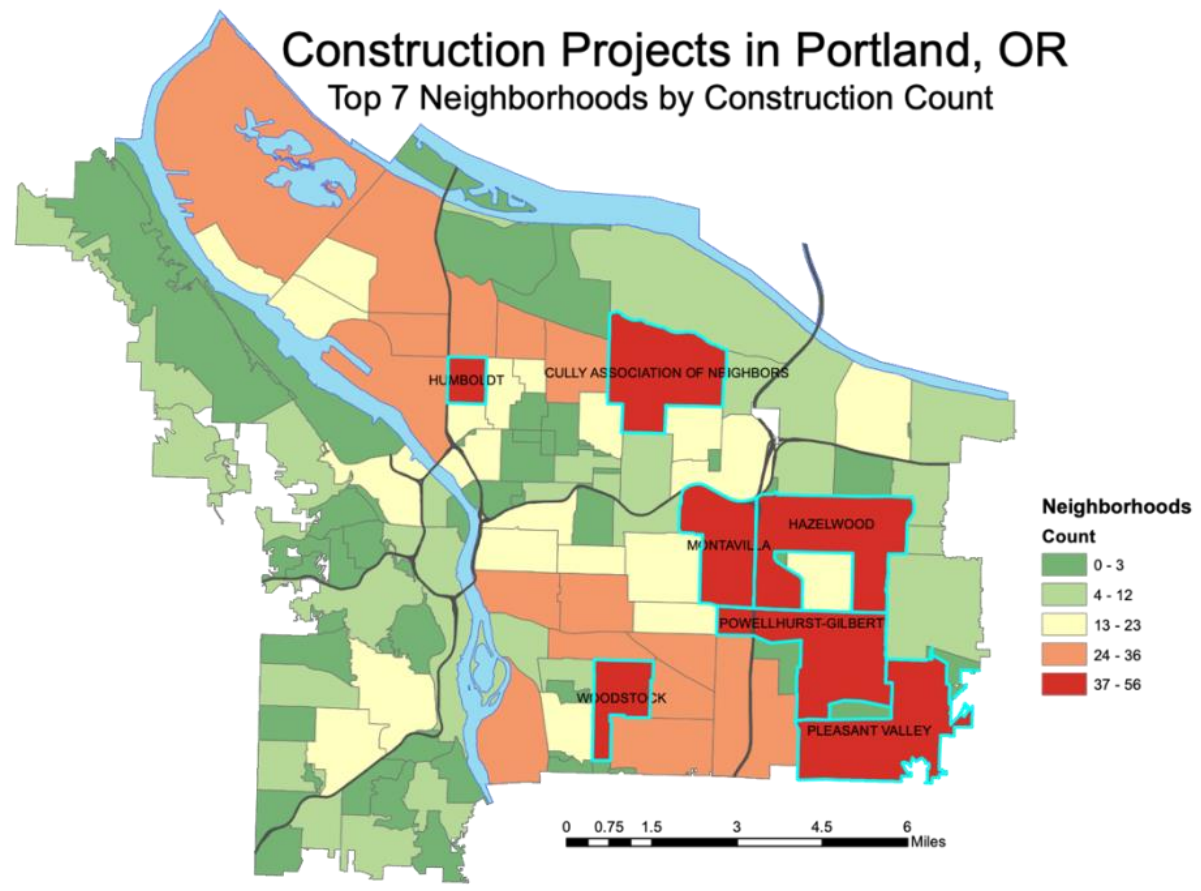

Figure 3.2. This map shows the 7 neighborhoods with the highest number of construction projects occurring in Portland for 2018: Humboldt, Cully, Woodstock, Montavilla, Hazelwood, PowellhurstGilbert, and Pleasant Valley.

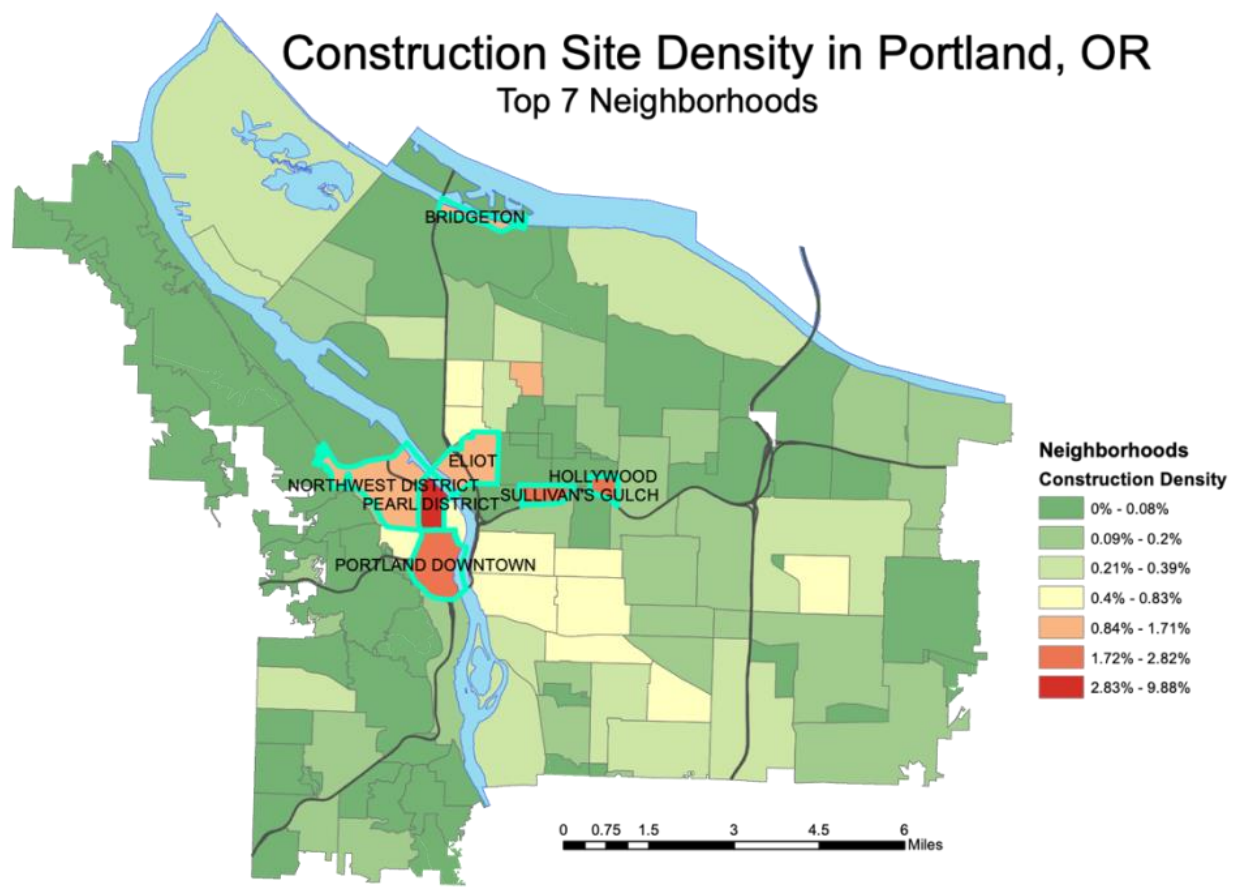

Figure 3.3. This map shows the 7 neighborhoods with the highest density of construction projects occurring in Portland for 2018: Downtown, Pearl District, Northwest District, Hollywood, Sullivan's Gulch, Eliot, and Bridgeton. Density equation: total number of square footage for construction projects/total square footage of neighborhood. 
To get a better sense of the potential vulnerability of each neighborhood to construction emissions, a vulnerability index was created. This index was created using the following variables: children younger than 5 years old, people greater than 65 years old, people of color, and people with poverty-level household incomes. Each of these variables were given a rank score between 1 and 3, which represent tertiles of the dataset (See Appendix B). The higher the number the greater the \% of people living that hold that characteristic according to the US Census information (US Census, 2018). This vulnerability index was the normalized to values between 1-3. While not all variables hold the same risk factor, for the purposes of this analysis, each of the four variables were weighted equally. The results of this can be seen in Figure 3.4.

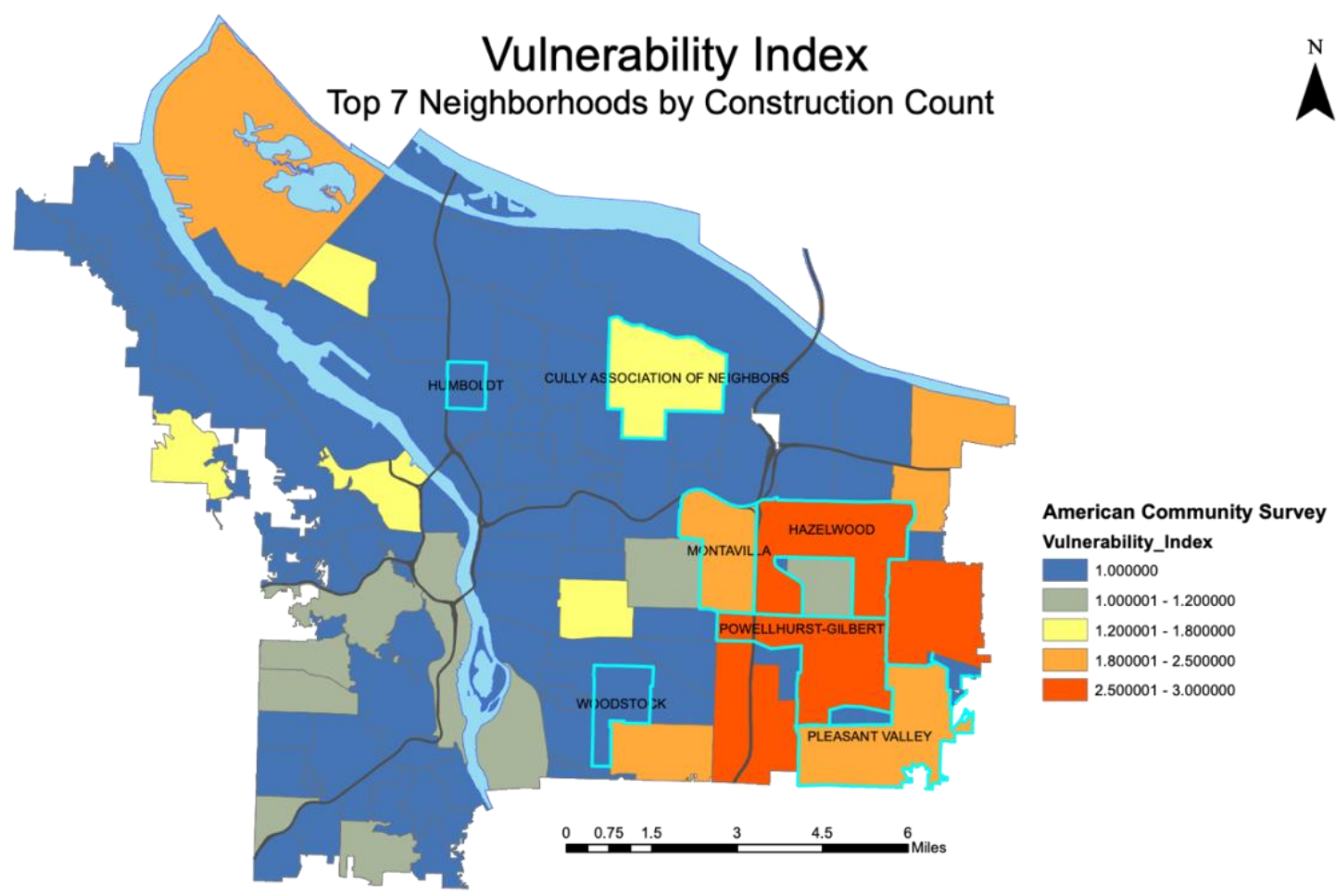

Figure 3.4. This map represents the vulnerability index score for each neighborhood. The highlighted neighborhoods represent the 7 neighborhoods with the highest number of construction projects occurring from Figure 3.2. 
Table 3.1. This table shows the 7 neighborhoods in Portland, OR with the highest number of construction projects and highest density of construction projects

\begin{tabular}{|c|c|c|c|c|c|c|}
\hline & \multicolumn{2}{|c|}{ Highest \# of Construction Projects } & \multicolumn{2}{c|}{ Highest Density of Construction Projects } \\
\hline \multirow{2}{*}{ Order } & Neighborhood & $\begin{array}{c}\text { \# of } \\
\text { Construction } \\
\text { Projects }\end{array}$ & $\begin{array}{c}\text { Vulnerability } \\
\text { Index }\end{array}$ & Neighborhood & $\begin{array}{c}\text { Construction } \\
\text { Density }\end{array}$ & $\begin{array}{c}\text { Vulnerability } \\
\text { Index }\end{array}$ \\
\hline 1 & $\begin{array}{c}\text { Powellhurst- } \\
\text { Gilbert }\end{array}$ & 56 & 3 & Pearl District & $9.9 \%$ & 1 \\
\hline 2 & Hazelwood & 54 & 3 & Portland & $2.8 \%$ & 1.2 \\
\hline 3 & Montavilla & 48 & 2 & Hollywood & $2.7 \%$ & 1 \\
\hline 4 & Cully & 42 & 1.8 & Sullivan's & $1.7 \%$ & 1 \\
\hline 5 & $\begin{array}{c}\text { Pleasant } \\
\text { Valley }\end{array}$ & 42 & 2.5 & Gulch & 1 \\
\hline 6 & Humboldt & 40 & 1 & Bridgeton & $1.2 \%$ & 1 \\
\hline 7 & Woodstock & 39 & 1 & Northwest & $1.3 \%$ & 1.5 \\
\hline
\end{tabular}

This spatial analysis has identified neighborhoods in Portland with the highest impact from construction potentially currently and in the near future (Table 3.1). It is intuitive that most of the larger neighborhoods located in the East side of the city would have the highest number of projects. However, it is worth noting that these do correspond in most cases with some of the neighborhoods with the highest rates of vulnerability to air pollution (e.g. Hazelwood and Powellhurst-Gilbert). The density perspective showed that most of the high-intensity and largescale projects are occurring near downtown, which makes sense given the higher rates of multistory buildings. The results of this exploratory analysis were used to help inform construction site selection for the field-monitoring work documented in the following section. 


\section{Section IV: Neighborhood Construction Mapping Project}

\section{Introduction}

Neighbor's for Clean Air (NCA) is a local Portland non-profit whose mission is to educate the public about local air pollution threats and tools to ensure everyone can breathe clean air (NCA, 2020). In doing this work, NCA has identified diesel from off-road engines in Portland as one of the primary sources of air pollution and wanted to develop a tool to help educate local communities. As a collaborative effort between PSU and NCA, the Neighborhood Potential Diesel Impact Tool idea was born. As a first step, the tool would be used to identify the potential diesel risks from construction because that has the biggest contribution to diesel PM from offroad sources in our urban environment (ODEQ, 2012).

The tool would be an interactive website that anyone could utilize, enter their address, and see what construction activity was occurring near them and what the impact could be. Because construction projects vary greatly, actual emissions at the site cannot be calculated. However, using data gathered in the field, as well as utilizing existing research ${ }^{3}$, we developed an algorithm to classify each site into three potential diesel impact (PDI) categories: low, medium, and high.

The information on the website primarily was written as part of this Master's project and copyedited for final web publication is available through: whatsinourair.org.

\section{Purpose and Goals}

The purpose of this tool is to inform the average Portland resident, meaning someone who may know very little about air pollution, about the possible impact of construction in their neighborhood. This includes both environmental and health risks associated with diesel pollution. Because of this primary goal, the website was tasked with digesting the complicated subject of atmospheric science into a format that is approachable and easy to understand.

After using the tool, the goal is that the reader would click on the final tab "Join Us", which leads them to learn more about Neighbors for Clean Air and redirects them to the NCA site for more ways to get involved and take action.

\footnotetext{
${ }^{3}$ See Section 3.
} 
The website has two primary pages: The Issue and The Mapping Tool. "The Issue" page is a long scrolling page designed to read like a story. The first panel introduces the issue: We all have the right to breath clean air. The webpage then explains diesel's contribution to air pollution and specifically the issue of diesel in urban areas like Portland, OR. The next few blocks of text outline the issue of older off-road equipment and the impacts that is has on our health and environment, especially for high-risk communities such as communities of color, pregnant people, children, and the elderly. The text on the website provides a high-level and easy to understand summary of the information detailed in Section 2 of this report because it is intended to inform people who may be hearing about this issue for the first time. The outline of this webpage is shown below, and general layout can be seen in Figure 4.1.

Outline of "The Issue" web page:

1. The issue

2. Diesel engines are a primary source of air pollution

3. Diesel pollution primarily comes from off-road engines in the Portland area

4. What is off-road equipment?

5. The emissions and impact of old diesel engines

6. Diesel engines endanger our health

7. Diesel pollution is an environmental justice issue

8. Pregnant people, children, and the elderly are most effected by air pollution

9. Environmental Impacts of Diesel Engines: The role of black carbon

10. We need a statewide Clean Diesel Standard

(19):

The Issue Mapping Tool Join Us

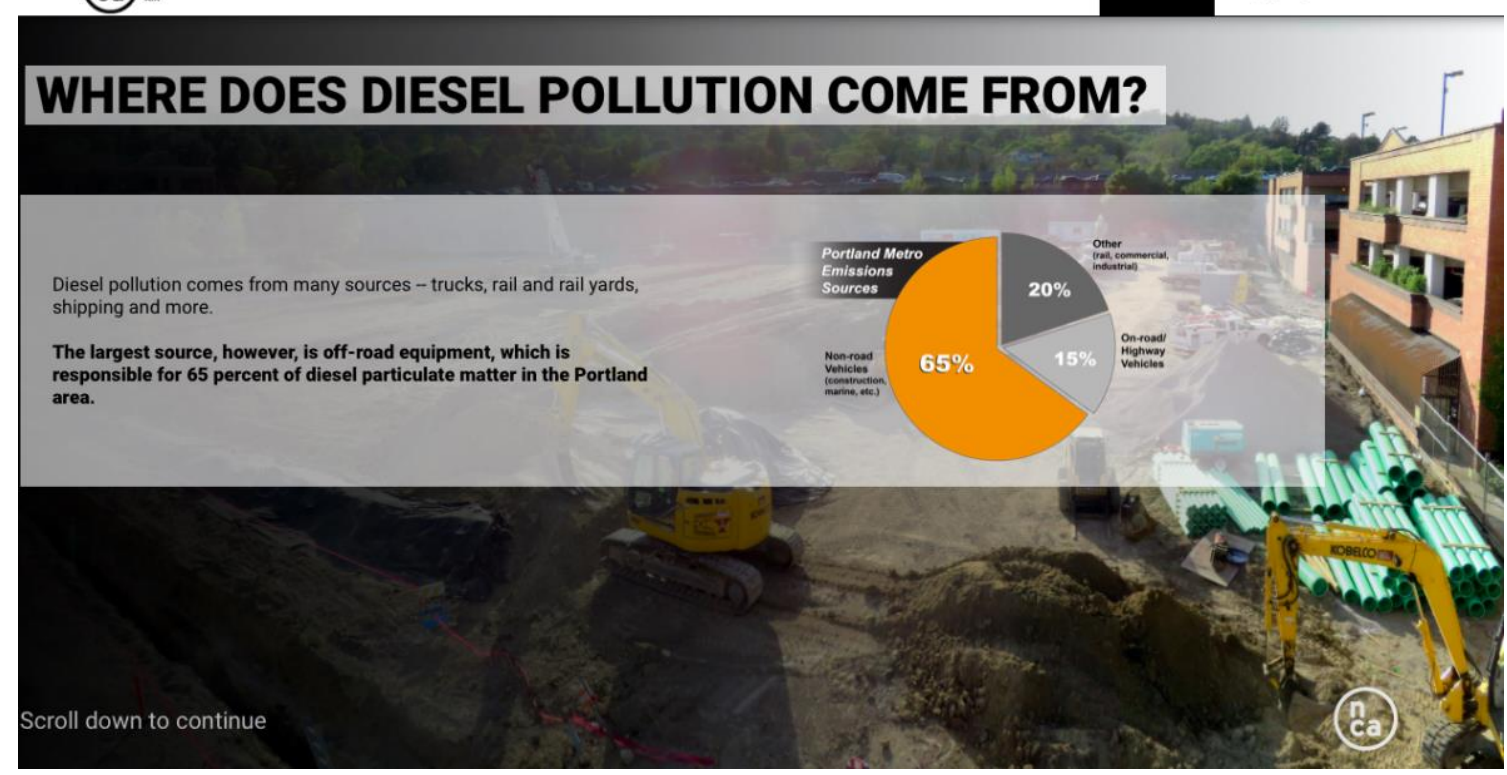

Figure 4.1. Section 3 of "The Issue" webpage. Stills of each text block is available in Appendix C. 
Images detailing each slide of the webpage are included in Appendix $\mathrm{C}$ or can be seen by visiting whatsinourair.org.

\section{Clean Diesel Standard}

In block 10 of "The Issue" web page, a modeling exercise was done to look at the impact that a clean diesel standard could have on pollution in Portland if all projects adhered to the standard. The Portland Metro Area does have a Clean Air Construction (CAC) program in place as of January 1, 2020. Currently, public agencies can volunteer to adopt the standards on projects that cost over a specified amount. The standards in this program mandate that all construction equipment on site must be Tier 4, the highest standard available for diesel engines presently, or must be retrofitted with a diesel particulate filter (City of Portland, 2020). As of July 2020, only the City of Portland, Multnomah County, Washington County, Port of Portland, and Metro have signed onto the program and only for projects costing $\$ 500,000$ or greater. ODOT oversees a lot of construction activity in Oregon but has not yet elected into the CAC program (ODEQ, 2020).

The modeling exercise, however, assumed a hypothetical scenario where all construction projects, both private and public, of any cost would adhere to the final standards of the CAC program, meaning only Tier 4 equipment can be used only on site. To get a baseline understanding of the diesel pollution currently in Portland from off-road engines, the Portland Air Toxics Solutions (PATS) project completed by the Oregon Department of Environmental Quality (DEQ) was used (ODEQ, 2012). This study was done in 2011 in attempt to spatially map air toxics in the Portland Metro area. In the final report, maps were created to model the average annual concentration of toxics in Portland for 2017, including Diesel PM which is shown in Figure 4.2. This study has limitations in that it is based on modeled data from 2007 that is being projected into 2017 and not on actual measured emissions. While this study does have many limitations, it is the best available dataset to use to look at the spatial distribution of air toxics in the region. For this project, only the city of Portland was included. 


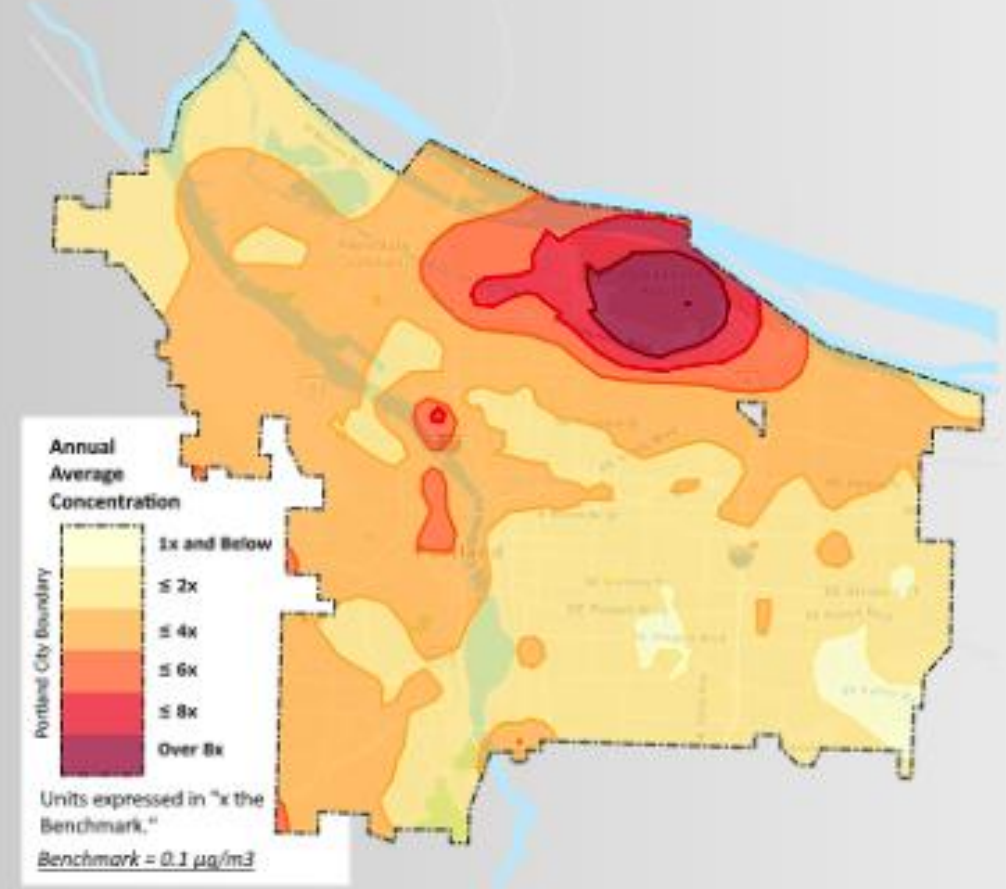

Figure 4.2. This map shows the Portland Air Toxic Solutions (PATS) data for Diesel Particulate Matter from non-road sources only in the city of Portland. This map shows the data as is with no changes from the original dataset. The units are represented in "times the Benchmark", which is $0.1 \mathrm{ug} / \mathrm{m} 3$.

The PATS dataset was modeled to show the estimated reduction in Diesel Particulate Matter if all construction projects occurring, regardless of budget or type of entity, were completed using Tier 4 technology. EPA's Motor Vehicle Emission Simulator (MOVES), version MOVES2014b, was used to model the percent reduction in Diesel PM from the existing tier distribution assumed for Portland ${ }^{4}$ to all Tier 4. To see the change in Tier Distribution for the modeled scenario, see Table 4.1. Two MOVES runs were completed: one for the baseline to get total emissions and the second for the all Tier 4 scenario. The baseline scenario resulted in 88.9 tons per year in Diesel PM and the All Tier 4 Scenario resulted in 17.8 tons per year. The difference between the two scenarios is 71.1 tons per year, which is an $80 \%$ reduction. The relative reduction in Diesel PM was then applied to the baseline map to get the map shown in Figure 4.3.

\footnotetext{
${ }^{4}$ MOVES Default for Multnomah County region.
} 
Table 4.1. This table shows the vehicle tier distribution of construction equipment assumed for each scenario. Actual tier distribution for the baseline scenario is unknown, so MOVES default fleet information was used.

\begin{tabular}{|l|l|l|}
\hline & Baseline Scenario & All Tier 4 Scenario \\
\hline Tier 0 & $7.5 \%$ & $0 \%$ \\
\hline Tier 1 & $15.4 \%$ & $0 \%$ \\
\hline Tier 2 & $15.2 \%$ & $0 \%$ \\
\hline Tier 3 & $16.3 \%$ & $0 \%$ \\
\hline Tier 4 & $45.5 \%$ & $100 \%$ \\
\hline $\begin{array}{l}\text { Total Diesel PM2.5 Emissions } \\
\text { from Construction Sector }\end{array}$ & 88.9 tons per year & 17.8 tons per year \\
\hline Reduction in Diesel PM & & \\
\hline
\end{tabular}

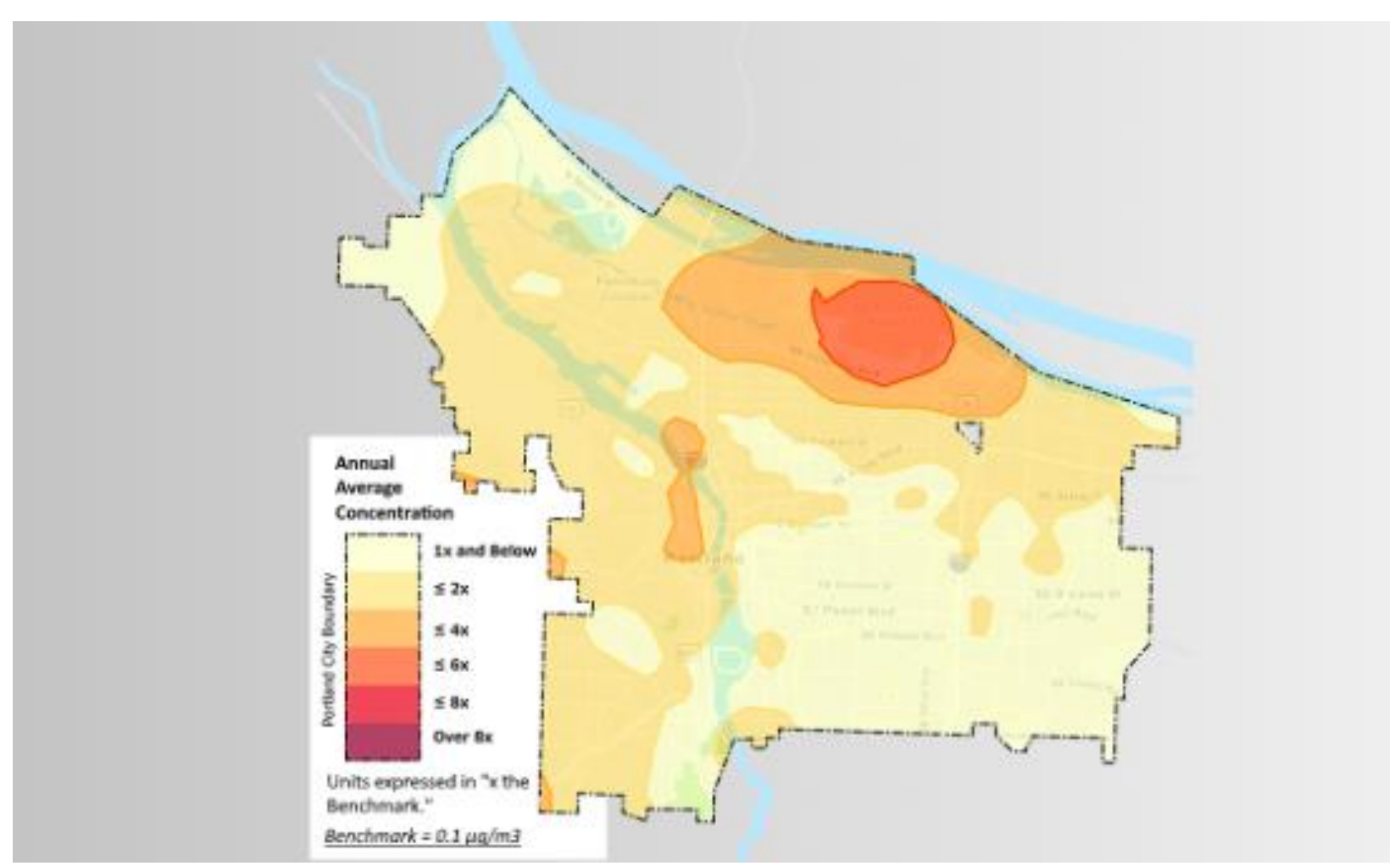

Figure 4.3. This map shows the PATS dataset for Diesel PM from non-road engines with the $80 \%$ reduction in Diesel PM applied from the MOVES modeling results detailed in Table 4.1. This hypothetical scenario assumes that all construction projects would be done using tier 4 equipment. 


\section{The Mapping Tool}

The "Mapping Tool" page is the interactive map which shows points where there is a permit application on file with the City of Portland within the past 10 years. Permit data on the site is pulled in through Portland Maps, which is updated weekly with new construction permits by the Portland Bureau of Development Services. The user can enter in any address or place a point on the map which then activates the buffer that shows construction permits nearby. The buffer can be adjusted in size from 500 meters to 1,500 meters. The range of years can also be adjusted to allow users to see any range of years from 2010 to present.

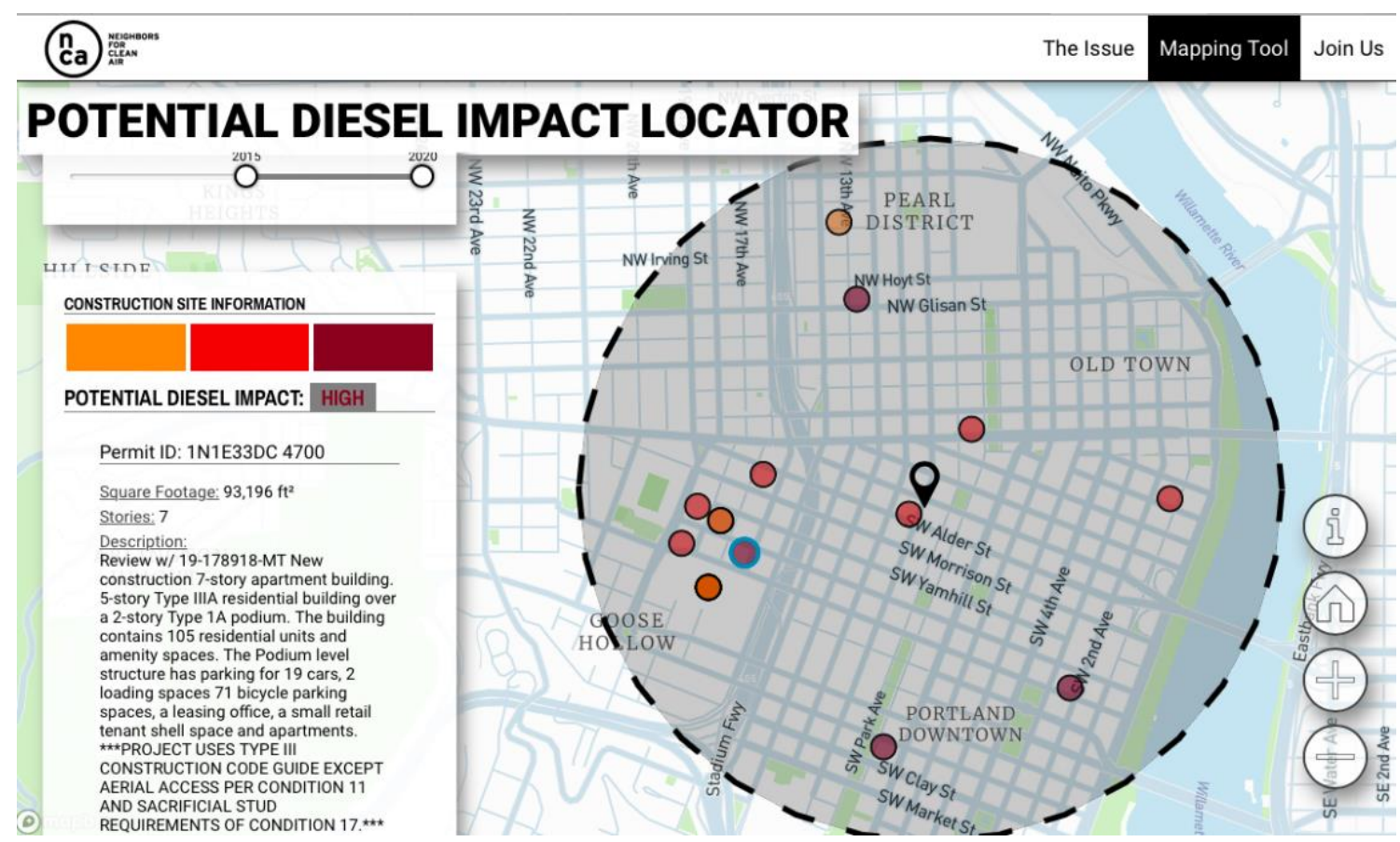

Figure 4.4. A still of the construction site mapping tool. This pin was put in downtown Portland and shows sites classified in each of the three PDI groupings.

Once the address or map pin is selected, the color-coded points indicate the level of Potential Diesel Impact (PDI) the site has. There are three corresponding levels each site can fall into: low (orange), medium (red), and high (maroon). When selecting a particular point, more information about the permit will show up in the left panel (see Figure 4.4).

Each construction site's ranking of low, medium, or high PDI is based on data that was included in the permit dataset. The sites are given a PDI score using the following algorithm:

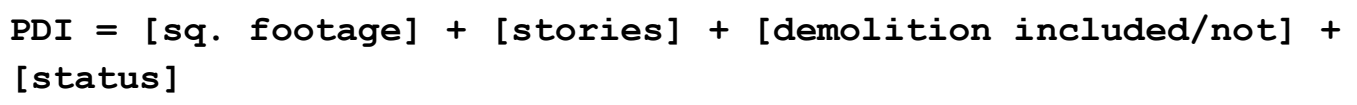


Each of these four variables were given a score between 1 and 4, from least impactful to most impactful. While emissions on a site vary by a lot more than these four characteristics, these were the best available metrics included in the permit dataset. Square footage refers to the total square footage of the building being constructed once complete. Stories refers to the total number of levels the building has. Demolition being included as a component of the project was also factored in, as well as the status of the project which takes into account current activity level. Further detail of each variable and the point value assigned to it is outlined in tables 4.2 and 4.3.

Table 4.2. The following table shows how many points a site is given for each of the variable's values, ranging from 1-4. The higher the point value indicates a higher likelihood of Potential Diesel Impact (PDI).

\begin{tabular}{c|cccc}
\multicolumn{1}{l}{$\begin{array}{l}\text { POINTS } \\
\text { ASSIGNED }\end{array}$} & SQUARE & & & \\
\hline $\mathbf{1}$ & FOOTAGE & STORIES & DEMOLITION & STATUS \\
\hline $\mathbf{2}$ & $10,000-49,999$ & $1-2$ & No Demolition & Under Inspection \\
$\mathbf{3}$ & $50,000-99,999$ & $5-5$ & - & - \\
$\mathbf{4}$ & 100,000 or more & - & Demolition & Under Review or \\
& & - & Included & Issued \\
\end{tabular}

Table 4.3. The following table shows the total point values associated with each level of PDI. For example, a construction site who's PDI equation equals 12 would be rated a high likelihood of PDI.

\begin{tabular}{lc}
\hline $\begin{array}{l}\text { Potential Diesel Impact } \\
\text { (PDI) Level }\end{array}$ & Rating \\
\hline High & $12-13$
\end{tabular}

Medium

8-11

Low

4-7 


\section{Field-Study: Ground-truthing the PDI Equation}

\section{Introduction}

The algorithm was first developed in an attempt to understand the potential pollution impact a construction site may have on an area based solely on information included in the permit dataset that is publicly available. Knowing that this would be used as a public education tool, categorizing sites into three groupings seemed to be a good approach to convey scale of the construction site.

The algorithm's point values (Table 4.2 and 4.3) were initially based on looking at the permit dataset. Information gathered from reading literature confirmed that the earthworks phase of construction is the most emission intensive ${ }^{5}$. To confirm that these PDI groupings were appropriate, field work was also done at construction sites in Portland to measure black carbon emissions.

The benchmark for Diesel Particulate Matter, which includes black carbon, is $0.1 \mathrm{ug} / \mathrm{m} 3$ in Oregon DEQ Portland Air Toxics Solutions report, which is health-based benchmark (2012). However, according to the DEQ SE Portland air quality monitoring station, the average ambient black carbon concentration in Portland exceeded this benchmark for September 2019-August 2020 is $0.35 \mathrm{ug} / \mathrm{m} 3 .{ }^{6}$ While there are many sources of black carbon in Portland, this study aims to look at construction's contribution to black carbon in local air quality.

\section{Methodology}

A total of 16 site visits were completed to active construction projects in Portland, OR. Of these site visits, 3 were made to a Low PDI site, 4 were made to Medium PDI sites, and 9 were made to High PDI sites. For more detail on site visits and location, please see Table 4.4 and Figure 4.5. Each site visit included monitoring directly near the construction activity, as well as surrounding blocks. Sites were chosen using the PDI algorithm and identifier tool from whatsinourair.org and selected based on whether or not the site was active and in the earthworks stage (meaning site excavation and foundation work).

An Aethlabs MicroAeth MA300 was used to measure black carbon at a one second time interval, later averaged to ten seconds. The MA300 has built-in GPS tracking which was used to produce spatial maps of pollutant dispersion. Site visits occurred during morning hours of operation due

\footnotetext{
${ }^{5}$ See Section 3.

${ }^{6}$ See Appendix D.
} 
to meteorological conditions that are more conducive to air monitoring (i.e. less wind and mixing of pollutants) and were generally taken between 7:00AM-10:00AM (working hours of site).

In addition to measuring black carbon, a field log was kept noting the conditions of the following variables and field measurements were not taken at times when conditions appeared to impact results (e.g. heavy rainfall, wildfire smoke).

1. Wind Speed \& Direction: Abstain from going out into the field during high wind due to the mixing and dilution of emissions.

2. Rain: When more than a light mist, abstain from taking field measurements.

3. Humidity: Document current humidity level and dew point

4. Temperature: Document temperature using hourly weather data for the city of Portland

5. Equipment activity variation: Site visits will be done randomly. Detailed equipment notes will be taken on what equipment is included, as well as photographs.

6. Background concentration of pollutants: To account for background pollutants, samples will be taken in the morning before activity starts or during a weekend day.

7. Emission interference: While sampling, equipment/vehicles may pass by (e.g. nonconstruction trucks, leaf blowers, etc.) and skew results. To account for this, a detailed log will be taken at each site with notes about non-construction equipment.

8. Pollutant Dispersion: Pollutants may travel far from the construction site. At each site, samples will be taken right around each site, as well as increasing circles of blocks around the construction site, up to a 3-block radius when able to.

9. Instrument issues: The time on the instrument is calibrated every time it is connected to a computer. Data will be exported weekly and cleaned/reviewed. If data appears to be off, lab tests will be performed.

10. Anomaly events: Wildfires or extreme snow events may interfere with measurements. Both of these typically are not present in Portland, so in these events samples would not be taken.

Table 4.4. The total number of visits of each construction site during working hours. For location information, see Figure 4.5.

\begin{tabular}{l|cccccc}
\multicolumn{2}{l}{ LOW } & MEDIUM & MEDIUM & HIGH & HIGH & \\
& SITE \#1 & SITE \#1 & SITE \#2 & SITE \#1 & SITE \#2 & TOTAL \\
\hline $\begin{array}{l}\text { NUMBER OF } \\
\text { VISITS }\end{array}$ & 3 & 2 & 2 & 7 & 2 & 17 \\
& & & & & &
\end{tabular}




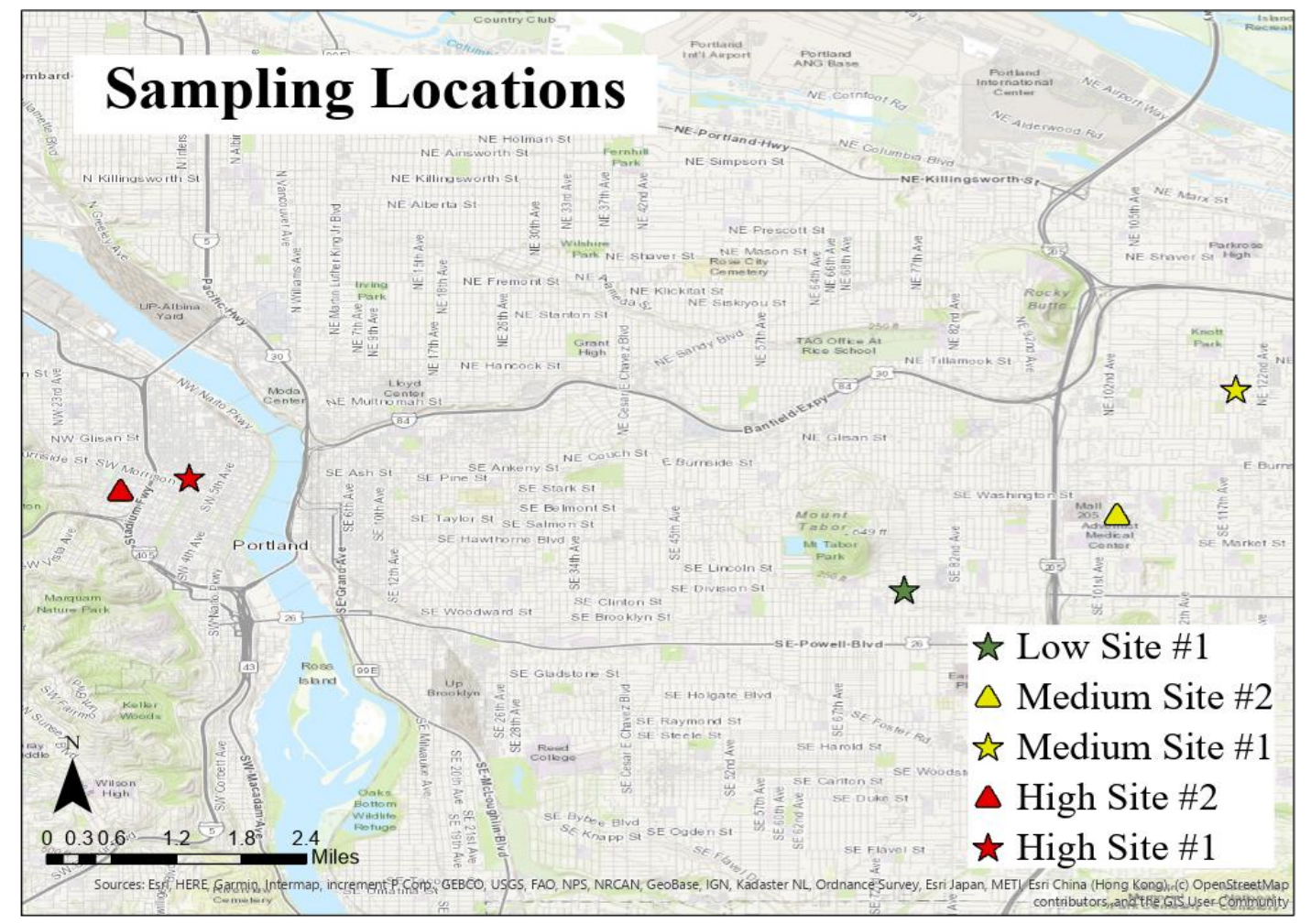

Figure 4.5. Locations of each construction site sampled for this study.

Because air pollutant data near sources tends to include periodic plumes, the analysis done with this data includes non-parametric tests due to the fact that we want to preserve highest values and not treat them as outliers. Air emissions from mobile sources such as construction sites will tend to have spikes of pollutants because the activity occurring on a site varies often and varying activities results in varied emissions levels.

To account for this, analysis was done in $\mathrm{R}$ including summary statistics of black carbon by site type, the distribution pattern of black carbon by site type, and the Kruskal-Wallis test was done to investigate whether or not there is a statistically significant difference in median black carbon levels between each site type. Spatial analysis was done in ESRI ArcGIS to visually understand the spatial impact construction sites have on the nearby areas; however, wind patterns greatly impact the spatial distributions.

Additional samples were taken near sites during non-working hours, which include prior to 7:00 AM during the week or during the weekend to get an ambient background concentration. 


\section{Results}

All data shown is sampled data for working hours of construction sites except where noted. Black carbon measured at all sites during working hours had a mean of $1.36 \mu \mathrm{g} / \mathrm{m} 3$ with a standard deviation of $2.18 \mu \mathrm{g} / \mathrm{m} 3$ and a maximum of $56.48 \mu \mathrm{g} / \mathrm{m} 3$. If you recall from the previous section, the benchmark for total diesel PM (black carbon and other particulate matter) is $0.1 \mu \mathrm{g} / \mathrm{m} 3$. Broken out by site size, the average black carbon observed was: $0.607 \mu \mathrm{g} / \mathrm{m} 3,1.48$ $\mu \mathrm{g} / \mathrm{m} 3$, and $1.65 \mu \mathrm{g} / \mathrm{m} 3$ (see Table 4.5). The average black carbon concentration by site size is also shown relative to the annual background concentration of $0.35 \mu \mathrm{g} / \mathrm{m} 3$ black carbon (ODEQ, 2020).

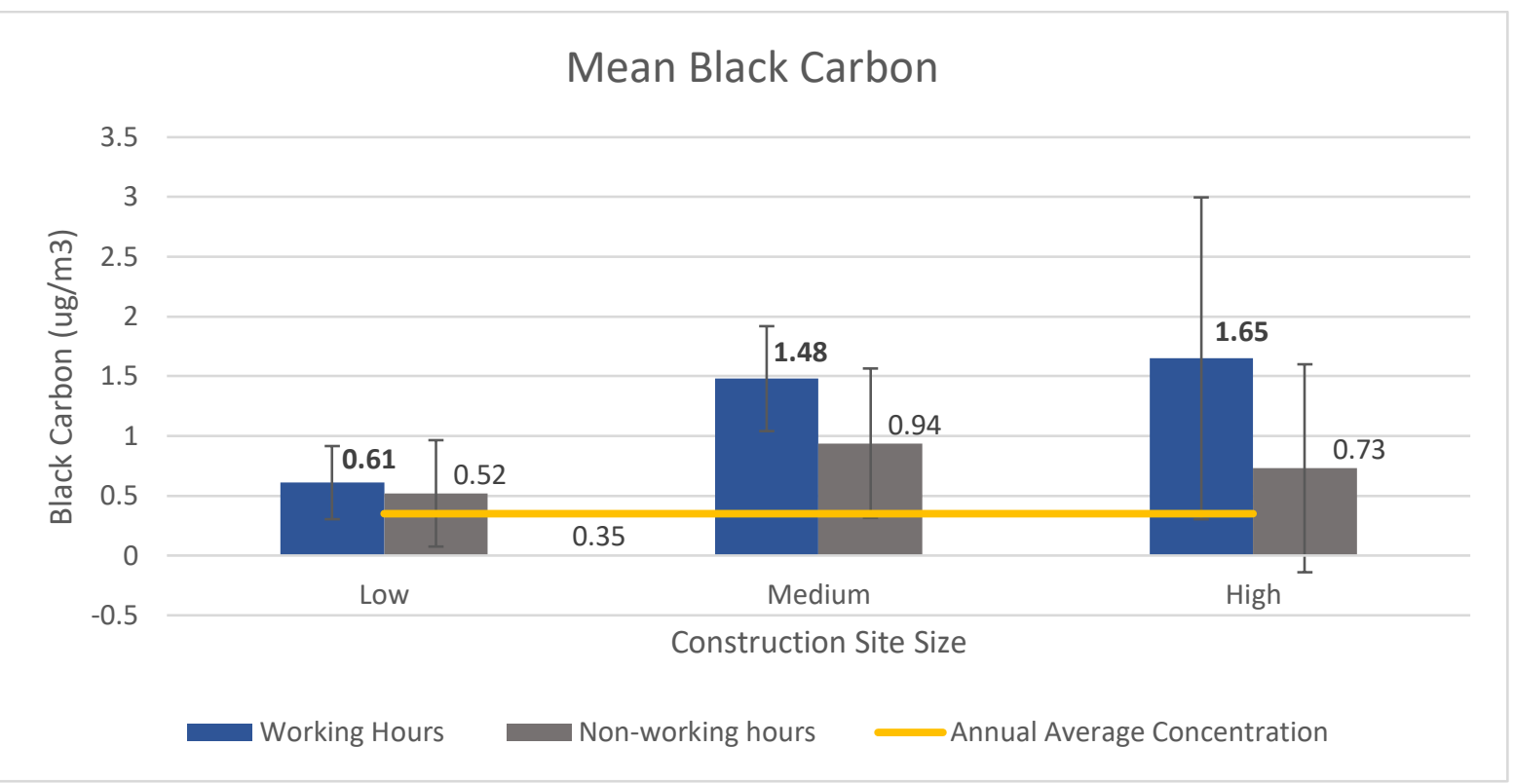

Figure 4.6. This graphically shows the mean black carbon concentration by PDI grouping, as well as an annual average of ambient black carbon of $0.35 \mu \mathrm{g} / \mathrm{m} 3$ from OR DEQ's monitoring station: SE Portland Lafayette.

Table 4.5. Summary statistics of black carbon measured by PDI grouping and across all sites during working hours.

\begin{tabular}{|l|l|l|l|l|l|l|}
\hline Site Type & \# of visits & $\begin{array}{l}\text { Sample } \\
\text { Size }(\mathbf{1 5} \\
\text { second } \\
\text { intervals })\end{array}$ & $\begin{array}{l}\text { Average } \\
\mathbf{B C} \\
(\boldsymbol{\mu g} / \mathbf{m 3})\end{array}$ & $\begin{array}{l}\text { Standard } \\
\text { Deviation } \\
(\boldsymbol{\mu g} / \mathbf{m 3})\end{array}$ & $\begin{array}{l}\text { Median } \\
\mathbf{B C} \\
(\boldsymbol{\mu g} / \mathbf{m 3})\end{array}$ & $\begin{array}{l}\text { Maximum } \\
\mathbf{B C}\end{array}$ \\
\hline Low Site & 3 & 1679 & 0.61 & 0.61 & 0.52 & 12.01 \\
\hline Medium Site & 4 & 937 & 1.48 & 0.89 & 1.31 & 7.78 \\
\hline High Site & 9 & 3913 & 1.65 & 2.69 & 1.05 & 56.48 \\
\hline $\begin{array}{l}\text { All Sites } \\
\text { (Aggregate) }\end{array}$ & $\mathbf{1 6}$ & $\mathbf{6 5 2 9}$ & $\mathbf{1 . 3 6}$ & $\mathbf{2 . 1 8}$ & $\mathbf{0 . 9 2}$ & $\mathbf{5 6 . 4 8}$ \\
\hline
\end{tabular}




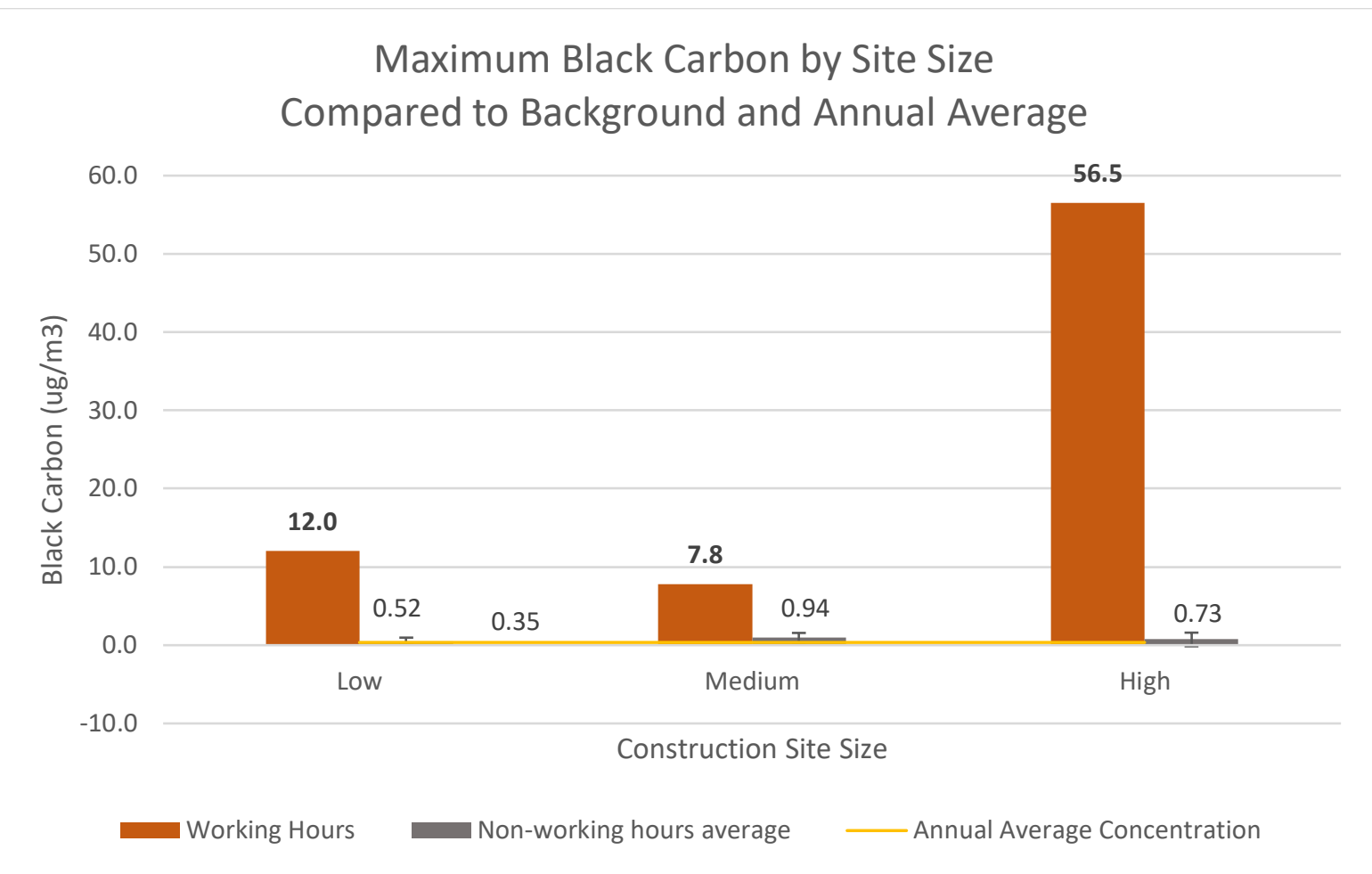

Figure 4.7. This chart graphically shows the maximums observed for each PDI group (orange). The non-working hours background concentration and annual averages are also graphed.

As mentioned previously, the black carbon data has a wide range of values and is not normally distributed because air quality impact is typically observed in plumes. The distribution of values, normality plot, and boxplot illustrate this in Figure 4.8. Due to standard instrument noise, some negative values were observed but frequency have been reduced by time-averaging at ten second intervals.

Because of the distribution, the Kruskal-Wallis test was used to analyze whether or not black carbon concentrations were significantly different by PDI ranking. The Kruskal-Wallis test is a non-parametric alternative to one-way ANOVA and was performed in R Studio. The results of the Kruskal-Wallis test shows that there is a significant difference between at least one of the groupings with a $99 \%$ confidence interval (chi-squared=1173.1, d.f=2, $\mathrm{p}<2.2 \mathrm{x} 10^{-16}$ ).

The next step was to determine which of the three groups (low, medium, high PDI) were statistically distinct from one another. The Wilcoxon signed-rank test, a pairwise comparison, was used to determine the statistical relationship between the three groups. The results concluded that all the three groups were significantly distinct from each other with a $99 \%$ confidence interval (see Table 4.7). 
Table 4.6. Kruskal-Wallis test statistics.

\begin{tabular}{|l|l|}
\hline \multicolumn{2}{|c|}{ Kruskal-Wallis Test } \\
\hline Chi-squared & 11173.1 \\
\hline df & 2 \\
\hline p-value & $<2.2 \times 10^{-16}$ \\
\hline
\end{tabular}

Table 4.7. Wilcoxon Signed-Rank Test results. Each PDI grouping was statistically distinct from one another.

\begin{tabular}{|l|l|l|}
\hline & High & Low \\
\hline Low & $<2 \times 10^{-16}$ & - \\
\hline Medium & $4 \times 10^{-16}$ & $<2 \times 10^{-16}$ \\
\hline
\end{tabular}


Figure 4.8. A histogram of black carbon concentrations across all sites is shown in the upper left, as well as a Q-Q plot (upper right). These illustrate the non-normal distribution of black carbon values. The boxplot shown (bottom) is broken out by PDI grouping and illustrate this non-normal distribution among PDI groupings as well.
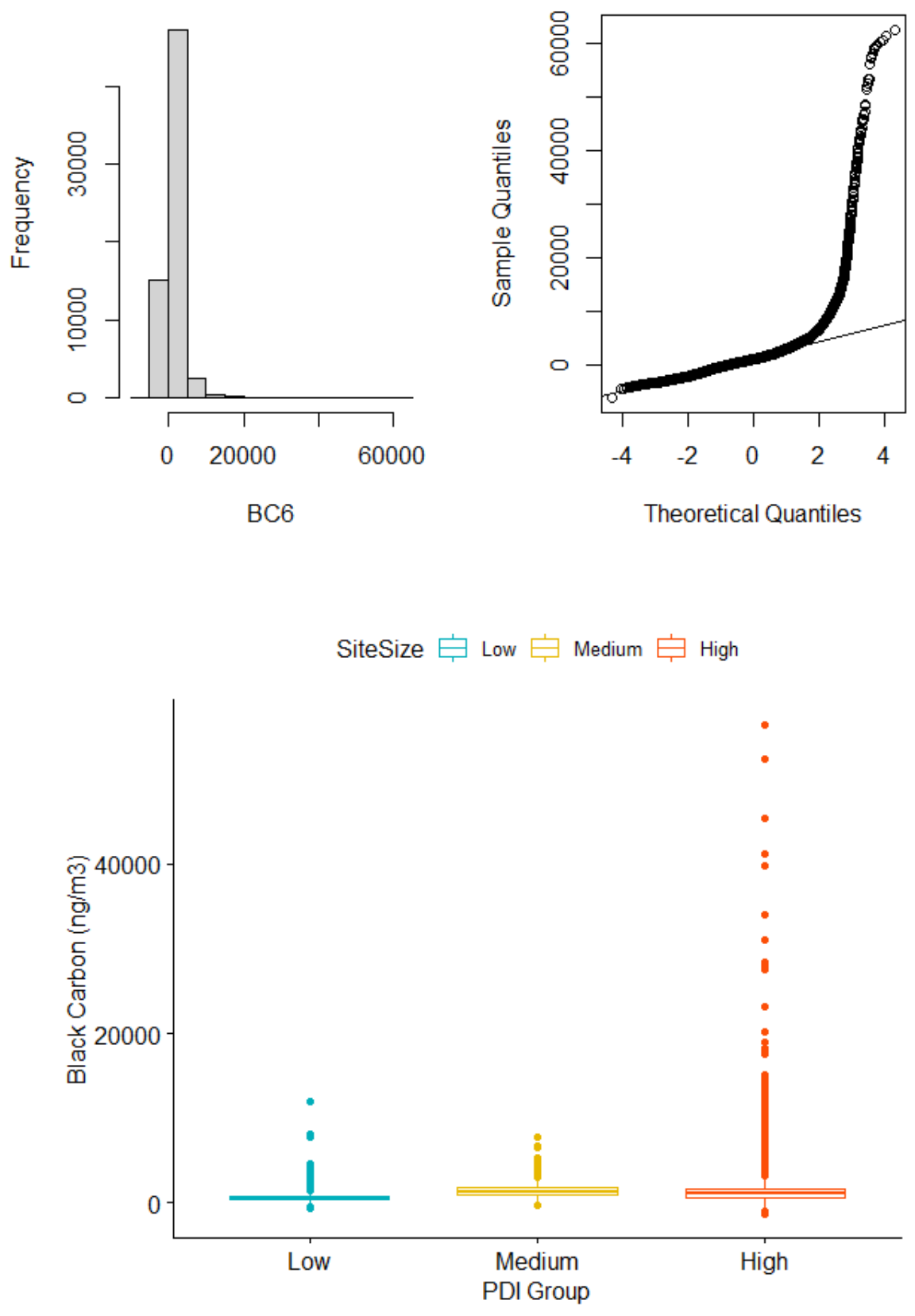
Figure 4.9. Distribution of Black Carbon by Site Size shown in both standard units and log-scale.

Low Site Distribution

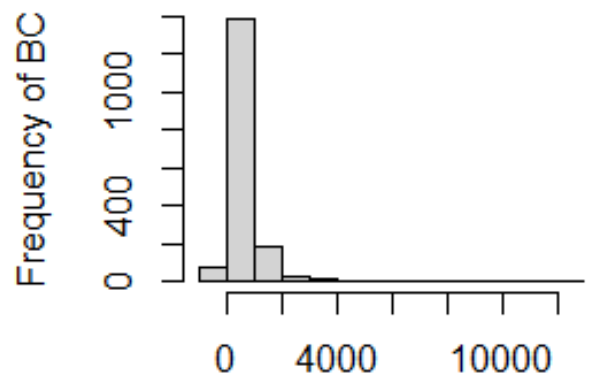

Black Carbon (ng/m3)

Low Site Distribution

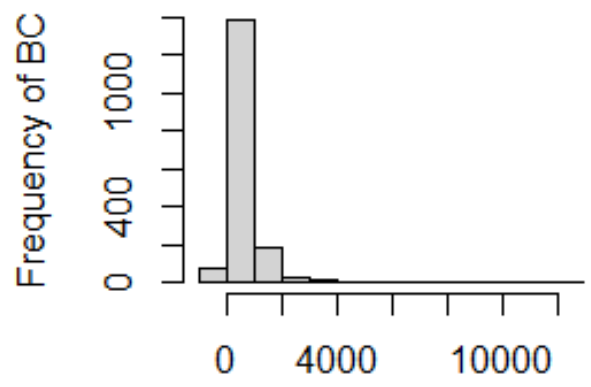

Black Carbon (ng/m3)
Low Site Distribution

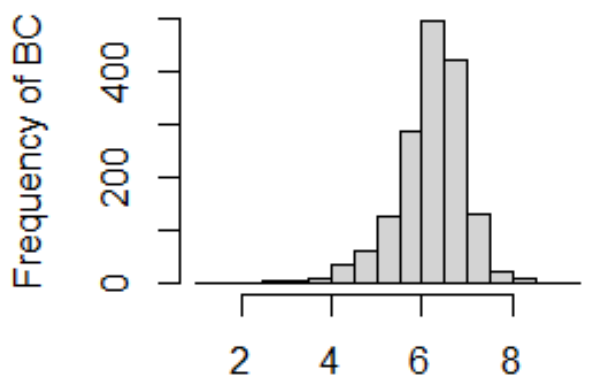

$\log ($ Black Carbon (ng/m3))

Low Site Distribution

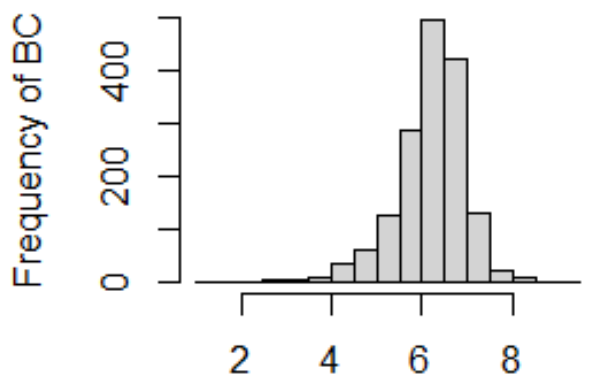

$\log ($ Black Carbon (ng/m3)) 
Medium Site Distribution

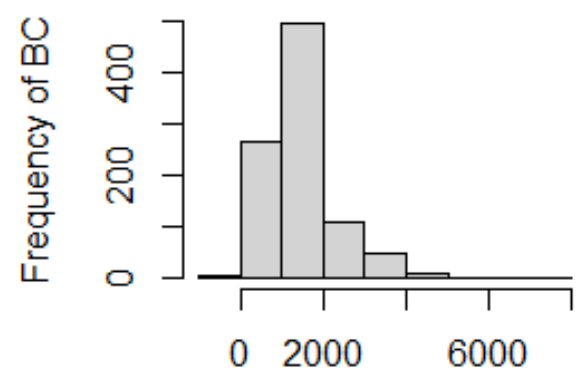

Black Carbon (ng/m3)

High Site Distribution

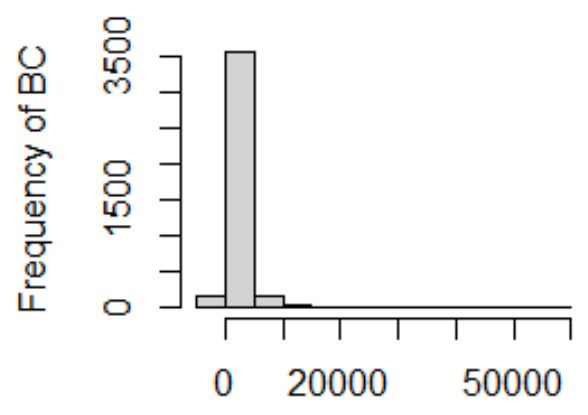

Black Carbon (ng/m3)
Medium Site Distribution

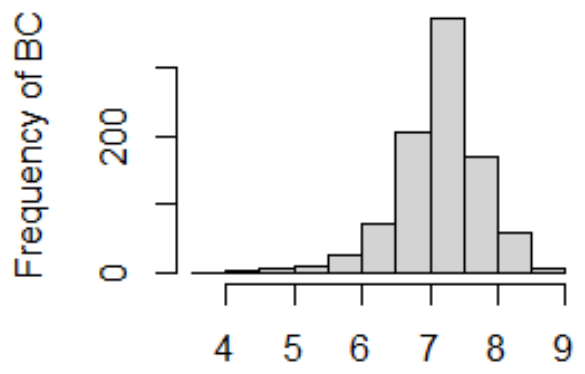

$\log ($ Black Carbon (ng/m3))

High Site Distribution

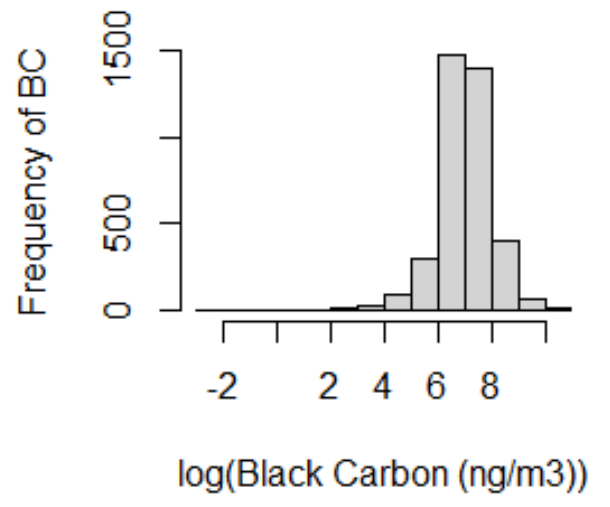

Some measurements were also taken at/near the sample site during non-working hours. For example, the High PDI Site \#1 is shown in Figure 4.10 on a weekday during working hours versus a weekend day. The average black carbon concentration at the site on a Monday, $09 / 16 / 19$, was $1.80 \mu \mathrm{g} / \mathrm{m} 3$ compared with $0.87 \mu \mathrm{g} / \mathrm{m} 3$ on a Saturday, 09/21/19. This particular Monday is also the day of the observed maximum measured at the size, which was $56.48 \mu \mathrm{g} / \mathrm{m} 3$. This value is 560 times the benchmark $(0.1 \mu \mathrm{g} / \mathrm{m} 3)$. While this value was the average for only a ten second interval, Figure 4.10 shows that there were many values above $25 \mu \mathrm{g} / \mathrm{m} 3$ throughout that morning during working hours. This figure also shows that elevated levels of black carbon can be seen within a couple block radius of the construction site, which illustrate the impact that construction can have in a local neighborhood.

It is also worth noting that this particular high PDI site started demolition in Spring 2019 and is currently still in the earthworks phase as of November 2020. While we have not been continuously monitoring this site, it seems likely that this site has had the potential to elevate 
black carbon in this local area for the past year and a half and may continue for the many more months.

Figure 4.10. This map shows black carbon measured at a high PDI construction site on a weekday versus a weekend day. The legend is consistent across both maps to show the difference in concentrations.

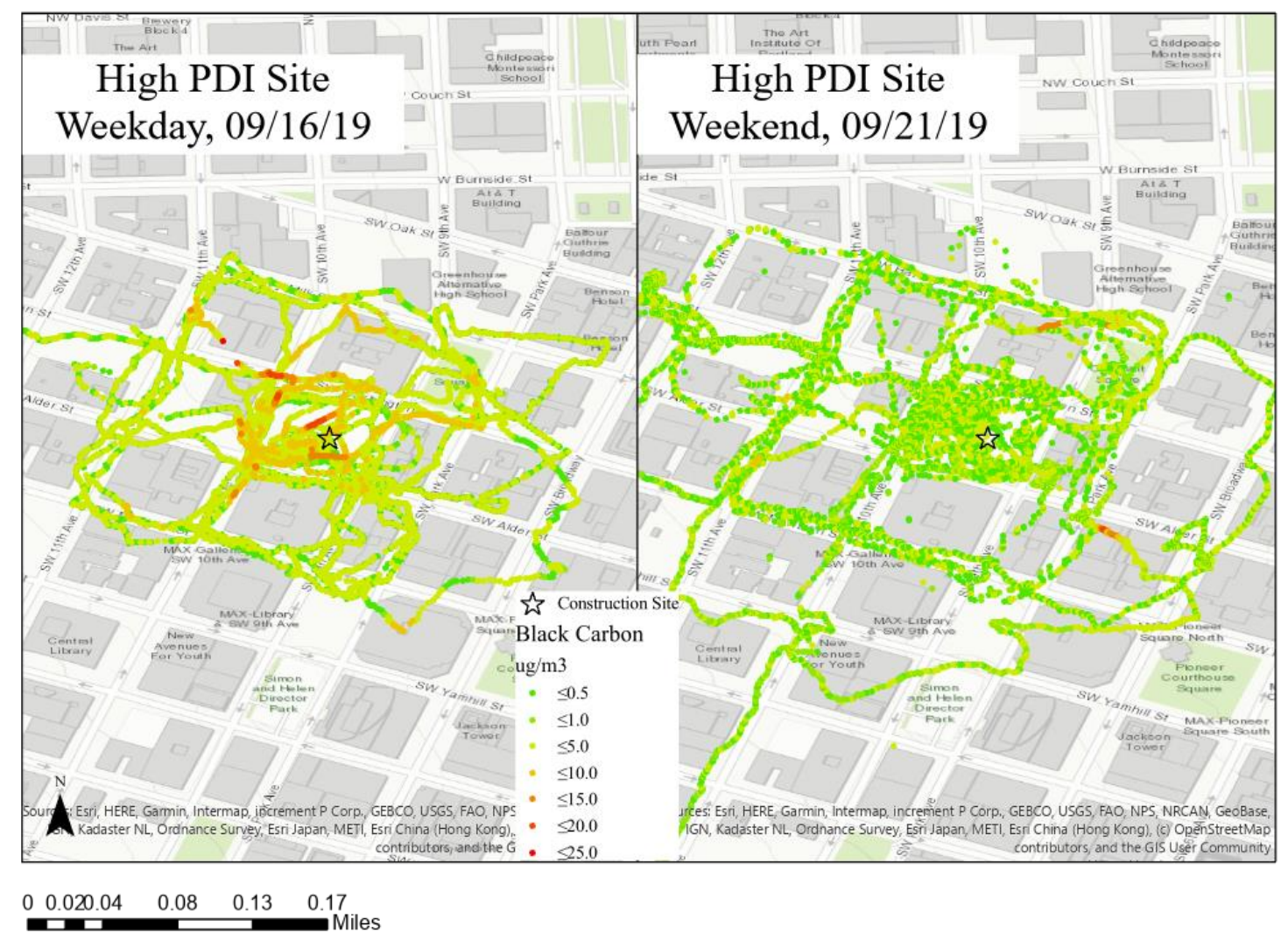

\section{Discussion}

The results of this field work have shown that there are elevated levels of black carbon in the air at and around construction sites in this city when compared to ambient concentrations. These results also presented evidence that the Potential Diesel Impact groupings (low, medium, high) presented statistically significant distinct black carbon emissions present at the construction. While the mean concentration of black carbon by site size did not vary too greatly, the high PDI sites had a much higher maximums (max of $56 \mu \mathrm{g} / \mathrm{m} 3$ ) and higher frequency of high-values than the low and medium sites. This illustrates that the high intensity sites can have significant impact on local air quality.

This data has also shown that elevated levels of black carbon can be detected within a couple block radius. While construction projects are temporary, these sites can still adversely impact neighborhood air quality. 


\section{Data Limitations}

This study does not attempt to understand the impact that multiple construction sites in one area can have on local air quality. Because this data has shown that emissions are not limited to the boundaries of the project site, more research about the cumulative impact of many projects occurring simultaneously could be helpful for local policymakers and regulation officials.

Other air pollutants and greenhouse gases, such as NOx, SO2, formaldehyde, and CO2, could be measured as well to better understand the black carbon contribution from construction sites. These pollutants, like black carbon, also have health and/or climate warming impacts. Measuring would give a better understanding of the total impact construction has on air quality.

Measuring black carbon at construction sites using only clean technology would also be helpful in understanding potential emission reductions. This would also be useful in understanding potential reduction to climate-warming and health impact as well, which was not attempted in this study.

Finally, future studies could be useful in understanding the emissions at all phases of a construction project. This study was done measuring emissions for a limited time-period during each site visit. If a long-term monitoring station could be set up at a construction site, then a better understanding of activity occurring on site would be better understood. 


\section{Section V. Conclusions \& Recommendations}

\section{Conclusions}

Diesel pollution from construction sites poses a threat to local air quality in Portland, OR and is the biggest contributor to diesel particulate matter in the urban area. There are currently little to no incentives for construction companies or their clients to use cleaner technology on site. The technology to reduce particulate matter from diesel engines exists but is not yet implemented on a large-scale.

Literature on this topic has suggested many possible strategies to reduce diesel emissions from construction sites. These include engine retrofits, diesel particulate filters, replacing older engines, using cleaner fuels, reducing idle time, ensuring proper maintenance of engines, and setting emission standards. Diesel Particle Filters are inexpensive compared to replacing equipment and can reduce emissions from construction vehicles by over $50 \%{ }^{7}$ These strategies include mandating the use of diesel particulate filters which are low-cost or new engines alltogether. While a couple of local public entities have agreed to cleaner technology on large-scale projects, there are still a lot of construction projects left to operate with any equipment.

The new Neighbors for Clean Air website, whatsinourair.org, serves as a tool to help educate the public on this issue. This issue of diesel PM is not well understood or communicated about by local news outlets, which has led to this issue going largely unnoticed. This website also allows residents to identify local construction projects occurring in their neighborhood currently or in the near future.

Using this tool, each construction site is given a ranking of low, medium, or high corresponding to the level of potential diesel impact (PDI) of particulate matter emissions at a given site. This rating is given based on permit characteristics, such as square footage and stories for the project. Scientific research, as well as the on-the-ground measurements done in this study, have shown that projects that are larger in scale (e.g. square footage, number of stories) have a higher likelihood to have elevated black carbon and particulate matter concentrations. Even small-scale projects have potential to negatively impact local air quality. Construction impacts, especially from high PDI-ranked sites, have the ability to travel throughout multiple blocks. Due to data limitations of the permits and variability of equipment used on a site, actual emissions associated for each site is difficult to predict.

\footnotetext{
${ }^{7}$ See Section 3.
} 


\section{Recommendations}

\section{All projects adhere to the Clean Air Construction Standards}

The city of Portland already has developed standards to help alleviate diesel emissions from construction sites. The current issue is that these are directed toward public agencies, large-scale projects, and are currently voluntary. If these standards were applied to all construction projects from both the public and private sector, diesel PM could be reduced as much as $80 \%$ in the city of Portland ${ }^{8}$. Without incentives for private companies to upgrade to newer technology, this reduction will be hard to achieve.

\section{Improve Construction Permit Detail}

To improve the ability for the web mapping tool to predict likelihood of emissions, more detail could be required in the construction permit information. Currently the construction permit dataset does not include any information about what types and how many of each equipment will be required, the activity rate of each piece of equipment, and the engine tier level of the equipment used. These pieces are key in being able to understand the emission rates from the vehicles on-site because emission rates are highest for older engines. This information would be helpful for the public to know so that they could better understand the risk at a specific construction site.

\section{Permits to be considered based on their impact on local air quality and public health}

The Portland Bureau of Development Services oversees construction permit applications in Portland. Construction permits are currently not withheld for concerns on local air quality impacts or public health impacts. Cleaner Air Oregon is a new program in Oregon which aims to bring in a health-based approach to setting air quality standards and regulations. However, the Cleaner Air Oregon program does not currently include mobile sources such as construction equipment. If a health-based approach was taken to solve the air pollution problem for the construction sector, permits could be used as a way to estimate emissions from the project at a point before construction begins to assess the impact the project may have on a neighborhood. This could also include accounting for active nearby construction projects as well. Currently, there does not appear to be any regulations on the number of construction projects that can occur in a single area at one time. In turn, communities can have several construction projects occurring at one-time, which cumulatively may have a large impact on air quality.

\section{Indirect Source Rule}

An indirect source rule could be one regulatory approach to reducing diesel emissions in the city. Indirect source rules limit aggregate air pollution emissions from facilities or sites that have high instances of mobile sources being used. These are sources that are not typically included in a facility's standard air quality permit. This would include construction sites, as well as railyards,

\footnotetext{
${ }^{8}$ See page 21.
} 
distribution centers, and parking lots. Currently there is an indirect source rule in Oregon, however it only applies to new construction of large parking lots in urban areas. Some work has been done by Neighbors for Clean Air and the Green Energy Institute to better understand how an indirect source rule could be effective in mitigating diesel emissions (Schlusser et. al., 2019).

\section{Good Neighbor Agreements}

Lastly, good neighbor agreements could be used as a way for neighborhoods to mobilize around reducing air quality impacts from construction projects. These agreements typically occur if enough neighborhood concern is raised about a particular source and often comes from neighborhood associations or neighborhood groups. The agreements are voluntary and allow the private entity and community members to compromise on project characteristics that meet both of their needs. This may include using only Tier 4 equipment on-site, putting restrictions on numbers of hours equipment can be operated per day, using alternative fuel sources on-site, or reducing overall scale of the project.

\section{Sticker Program \& Citizen Science Tool}

One of the challenges in understanding the emission concentrations at a construction site is due to the fact that it is extremely difficult to identify what engine tier a piece of equipment is operating with. To work around this issue, a sticker program has been implemented in California as a way to easily identify the engine tier associated with on-site equipment. A similar program could be utilized in Oregon, which would allow for anyone to easily identify the emission rates you might expect. The table in Appendix E includes the emission standards for each engine tier. One could use this table to create a citizen science tool where anyone could enter in the number of equipment they observed on a particular site and the sticker color (i.e. engine tier) and calculate the estimated emissions they might expect at that site per workday. Given that $70 \%$ of emissions from construction sites are from nine pieces of equipment, one could prioritize those vehicles.

\section{Areas of Future Research}

Because little research has been done to date on construction impacts on air quality, there are a lot of opportunities for further studies. Studies to better understand short-term health effects of these temporary, but sometimes very high-emitting sources, should be done to better understand the impact on public health in local communities, especially those that may be facing other disadvantages already.

This study could also be continued to measure black carbon at construction sites of various sizes and scales. With more samples, a regression analysis could be done to examine the relationship between the construction permit characteristics and average black carbon concentration measured on site to determine which factors impact emissions most heavily.

Long-term monitoring studies on construction sites are also very limited. Setting up air quality monitoring equipment on a site for the entire duration of a construction project would be useful 
in understanding the impact different phases have on local air quality. This could require cooperation from construction entities, which may be difficult to achieve.

Another area of interest would be to understand the impact that multiple construction projects occurring in a close proximity has on air quality. In residential neighborhoods, the construction projects are more likely to be small-scale, however, if multiple small-scale projects are occurring simultaneously, then local air quality may be more heavily impacted.

Black carbon and particulate matter concentrations at construction sites where all tier 4 equipment is being used would also be interesting to study. This would allow policymakers to better understand the possible reduction in emissions from upgrading to cleaner and newer technology. Large projects using tier 4 equipment, or those retrofitted with diesel particulate filters, would be most interesting to see and compare against the standard fleet used. 


\section{References}

Alexis, N. E., \& Carlsten, C. (2014). Interplay of air pollution and asthma immunipathogenisis: A focused review of diesel exhuast and ozone. International Immunopharmacology, 23, 347-355.

Andreae, M. O., \& Gelencser, A. (2006). Black carbon or brown carbon? The nature of lightabsorbing carbonaceous aerosols. Atmospheric Chemistry and Physics, 6, 3131-3148.

Araújo, I. P. S., Costa, D. B., \& de Moraes, R. J. B. (2014). Identification and Characterization of Particulate Matter Concentrations at Construction Jobsites. Sustainability, 6(11), 7666-7688.

Banzhaf, S., Ma, L., \& Timmins, C. (2019). Environmental justice: The economics of race, place, and pollution. The Journal of Economic Perspectives, 33(1), 185-208.

Betts, K. S. (2011). Road rage? The role of diesel particulate matter in lung inflammation. Environmental Health Perspectives, 119(3), A132.

Bond, T. C., Doherty, S. J., Fahey, D. W., Forster, P. M., Bernsten, T., DeAngelo, B. J., Flanner, M. G., Ghan, S., Karcher, D., Koch, D., Kinne, S., Kondo, Y., Quinn, P. K., Sarofim, M. C., Schultz, M. G., Schulz, M., Venkataraman, C., Zhang, H., Zhang, S., Bellouin, N., Guttikunda, S. K., Hopke, P. K., Jacobsen, M. Z., Kaiser, J. W., Klimont. Z., Lohmann, U., Schwarz, J. P., Shindell, D. Storelvmo, T., Warren, S. G., \& Zender, C. S. (2013). Bounding the role of black carbon in the climate system: A scientific assessment. Journal of Geophysical Research: Atmospheres, 118, 5380-5552.

California Air Resources Board. (2018). Diesel exhaust and health. https://ww2.arb.ca.gov/resources/overview-diesel-exhaust-and-health

Codispoti, C. D., LeMasters, G. K., Ryan, P. H., Villareal, M., Burkle, J. W., Lockey, J. E., Khurana Hershey, G. K., Levin, L. S., \& Bernstein, D. I. (2008). Allergic rhinitis in three year old children with high exposure to diesel exhaust: The Cincinnati childhood allergy and air pollution study (CCAAPS). Journal of Allergy and Clinical Immunology, 121(2), S66.

Diaz-Robles, L. A., Fu, J. S., \& Reed, G. D. (2008). Modeling and source apportionment of diesel particulate matter. Environment International, 34, 1-11.

Donaldson, K., Brown, D., Clouter, A., Duffin, R., MacNee, W., Renwick, L., Tran, L., \& Stone, 
V. (2000). The impact of polycyclic aromatic hydrocarbons and fine particles on pregnancy outcome. Environmental Health Perspectives, 108(12), 1159-1164.

Faber, P., Drewnick, F., \& Borrmann, S. (2015). Aerosol particle and trace gas emissions from earthworks, road construction, and asphalt paving in Germany: Emission factors and influence on local air quality. Atmospheric Environment, 122, 662-671.

Font, A., Baker, T., Mudway, I. S., Purdie, E., Dunster, C., \& Fuller, G. W. (2014). Degradation in urban air quality from construction activity and increased traffic arising from a road widening scheme. Science of the Total Environment, 497-498, 123-132.

George, L. A., Rao, M., \& Orlando, P. (2019). Reducing health impact of diesel exhaust: Challenges and opportunities [Presentation]. Retrieved from: https://www.oregonlegislature.gov/dembrow/workgroupitems/719\%20Dr\%20Linda\%20George\%20Presentation\%20on\%20Health\%20Impacts.pdf

Goldberg, E. D. (1985). Black carbon in the environment: Properties and distribution.J. Wiley \& Sons.

Gorska, M. M., Alam R., \& Lengberg, J. (2015). Pre-pregnancy exposure to diesel exhaust particles predisposes offspring to asthma. Journal of Allergy and Clinical Immunology, 135(2), AB283.

Kholod, N., \& Evans, M. (2016). Reducing black carbon emissions from diesel vehicles in Russia: An assessment and policy recommendations. Environmental Science and Policy, $56,1-8$.

Long, C. M., Nascarella, M. A., \& Valberg, P.A. (2013). Carbon black vs. black carbon and other airborne materials containing elemental carbon: Physical and chemical distinctions. Environmental Pollution, 181, 271-286.

Metzger, K. B., Tolbert, P. E., Klein, M., Peel, J. L., Flanders, W. D., Todd, K., Mulholland, J. A., Ryan, P. B., \& Frumkin, H. (2004). Ambient air pollution and cardiovascular emergency department visits. Epidemiology, 15(1), 46-56.

Neighbors for Clean Air. (2020). What We Do. https://neighborsforcleanair.org/whatwedo/

Ntziachristos, L., Ning, Z., Geller, M. D., Sheesley, R. J., Schauer, J. J., \& Sioutas, C. (2007). Fine, ultrafine and nanoparticle trace element compositions near a major freeway with a high heavy-duty diesel fraction. Atmospheric Environment, 41, 5684-5696. 
Oregon Department of Environmental Quality. (2012). Portland Air Toxics Solutions committee report and recommendations (DEQ 11-AQ-048). https://www.oregon.gov/deq/ FilterDocs/PATS2012.pdf

Oregon Department of Environmental Quality. (2020). Cleaner Air Oregon Fact Sheets. https://www.oregon.gov/deq/aq/cao/Pages/CAO-Fact-sheets.aspx

Oregon Department of Environmental Quality. (2020). Oregon Nonroad Diesel Equipment Survey and Emissions Inventory. Submitted by: Eastern Research Group, Inc.

Rasdorf, W., Frey, C., Lewis, P., Kim, K., Pang, S., Abolhassani, S. (2010). Field procedures for real-world measurements of emissions form diesel construction vehicles. Journal of Infrastructure Systems, 16(3), 216-225.

Salam, M. T., Islam, T., \& Gilliland, F.D. Recent evidence for adverse effects of residential proximity to traffic sources on asthma. Current Opinion in Pulmonary Medicine, 14(1), 3-8.

Schlusser, A., Blumenstein, L., \& Smith, N. (July 2019). Deconstructing diesel: A law \& policy roadmap for reducing diesel emissions in the Portland metropolitan area. Green Energy Institute at Lewis \& Clark Law School.

Tessum, C. W., Apte, J. S., Goodkind, A., L., Muller, N. Z., Mullins, K. A., Paolella, D. A., Polasky, S., Springer, N. P., Thakrar, S. K., Marshall, J. D., \& Hill, J. D. (2019). Inequity in consumption of goods and services adds to racial-ethnic disparities in air pollution exposure. Proceedings of the National Academy of Sciences of the United States of America, 116(13), 6001-6006.

United States Census Bureau. (2010). Summary of Population and Housing Characteristics, 2010. https://www.census.gov/programs-surveys/decennial-census/decade/decennialpublications.2010.html

United States Environmental Protection Agency. (2012). Report to Congress on black carbon. https://19january2017snapshot.epa.gov/www3/airquality/blackcarbon/2012report/ fullreport.pdf

United States Environmental Protection Agency. (2016). Nonroad Compression-Ignition Engines: Exhaust Emission Standards. https://nepis.epa.gov/Exe/ZyPDF.cgi?Dockey=P100OA05.pdf 
United States Environmental Protection Agency. (2020). NAAQS Table.

https://www.epa.gov/criteria-air-pollutants/naaqs-table

Zavala, M., Huertas, J. I., Prato, D., Jazcilevich, A., Aguilar, A., Balam, M., \& Molina, L. T.

(2017). Real-world emissions of in-use off-road vehicles in Mexico. Journal of the Air \& Waste Management Association, 67(9), 958-972.

Zhang, H., Magara-Gomez, K., Olson, M., Okuda, T., Walz, K., Schauer, J., \& Kleeman, M. (2015). Atmospheric impacts of black carbon emission reductions through the strategic use of biodiesel in California. The Science of the Total Environment, 538, 412-422. 


\section{Appendix A: EPA Engine Class Definitions}

Table A1. EPA Engine Type Categories and Definitions

Source Type Definition

\section{On-Road Diesel \\ Heavy Duty Vehicles}

Off-Road Equipment

- Diesel

\section{Vehicles with a gross weight rating of 8,500 or more pounds}

Although "off-road" is used to refer to all transportation sources that are not on-highway, this section addresses nonroad equipment other than locomotives, aircraft, or commercial marine vessels. They include nonroad engines and equipment, such as lawn and garden equipment, construction equipment, engines used in recreational activities, portable industrial, commercial, and agricultural engines.

Locomotives The locomotive sector includes railroad locomotives powered by diesel-electric engines.

On-Road Diesel Light Duty Vehicles Commercial Marine Vessels
Vehicles with a gross weight rating of 8,499 or less pounds

The CMV sector includes boats and ships used either directly or indirectly in the conduct of commerce or military activity. The majority of vessels in this category are powered by diesel engines that are either fueled with distillate or residual fuel oil blends. 


\section{Appendix B: Additional Figures for Spatial Analysis of Construction Sites}

Table B1. An overview of the datasets used for the spatial analysis in Section 3.

\begin{tabular}{|l|l|l|l|l|}
\hline Key Datasets: & Description & Scale & File Type & Source \\
\hline $\begin{array}{l}\text { PDX Construction } \\
\text { Sites }\end{array}$ & $\begin{array}{l}\text { Permits issued for } \\
\text { construction sites } \\
\text { year, 2018) }\end{array}$ & Addresses & $\begin{array}{l}\text { CSV file } \\
\text { with } \\
\text { addresses }\end{array}$ & $\begin{array}{l}\text { Portland Bureau of } \\
\text { Development } \\
\text { Services }\end{array}$ \\
\hline $\begin{array}{l}\text { American } \\
\text { Community Survey } \\
\text { Demographics }\end{array}$ & Age, Race, Income, & $\begin{array}{l}\text { Census } \\
\text { Tract }\end{array}$ & Shapefile & $\begin{array}{l}\text { US Census } \\
\text { converted to } \\
\text { Shapefile by Metro } \\
\text { (RLIS) }\end{array}$ \\
\hline $\begin{array}{l}\text { PDX } \\
\text { Neighborhoods }\end{array}$ & $\begin{array}{l}\text { Neighborhood } \\
\text { Boundaries }\end{array}$ & UGB & Shapefile & Metro (RLIS) \\
\hline City Boundaries & City Boundaries & City & Shapefile & Metro (RLIS) \\
\hline Streets Locator & Address data & UGB & Locator & Metro (RLIS) \\
\hline Reference Datasets: & Major Rivers & UGB & Shapefile & Metro (RLIS) \\
\hline Rivers & Major Freeways & UGB & Shapefile & Metro (RLIS) \\
\hline Freeways & & & & \\
\hline
\end{tabular}

Vulnerability Index $=[$ Rank_5yrs $]$ * .25 +[Rank_65plus $]$ * .25+ [Rank_POC] * .25 + [Rank_Poverty] * .25 
Table B2. Each of the four variables used for the vulnerability index calculation, shown above. Each variable was weighted equally for simplicity.

\begin{tabular}{|l|l|l|l|l|l|l|l|}
\hline Age $<\mathbf{5}$ & Rank & Age 65+ & Rank & $\begin{array}{l}\text { People } \\
\text { of Color }\end{array}$ & Rank & Poverty & Rank \\
\hline Tertile 1 & 1 & Tertile 1 & 1 & Tertile 1 & 1 & Tertile 1 & 1 \\
\hline Tertile 2 & 2 & Tertile 2 & 2 & Tertile 2 & 2 & Tertile 2 & 2 \\
\hline Tertile 3 & 3 & Tertile 3 & 3 & Tertile 3 & 3 & Tertile 3 & 3 \\
\hline
\end{tabular}

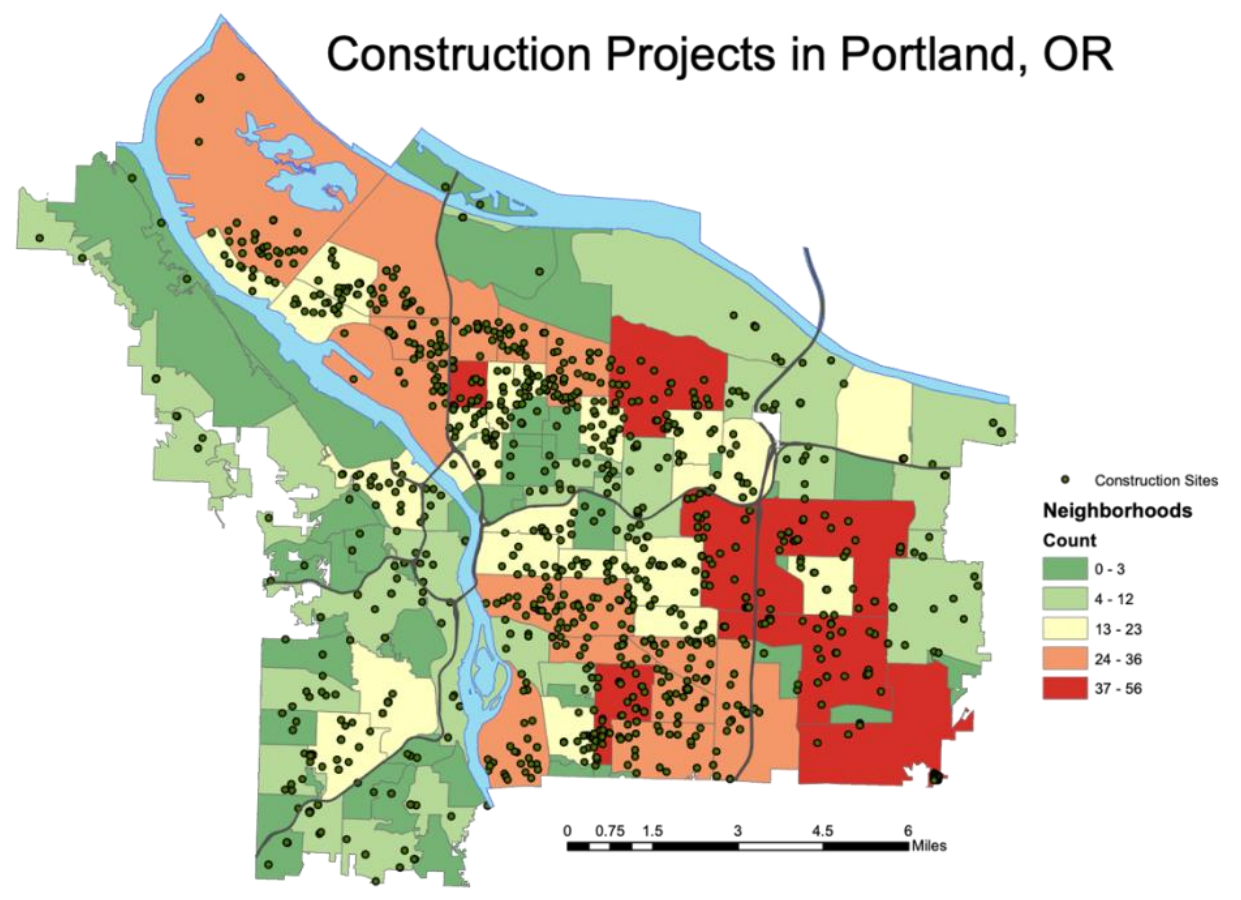

Figure B1. This map is similar to the one shown in Section 3 (Figure 3.2), but also includes each construction site as a point feature. 


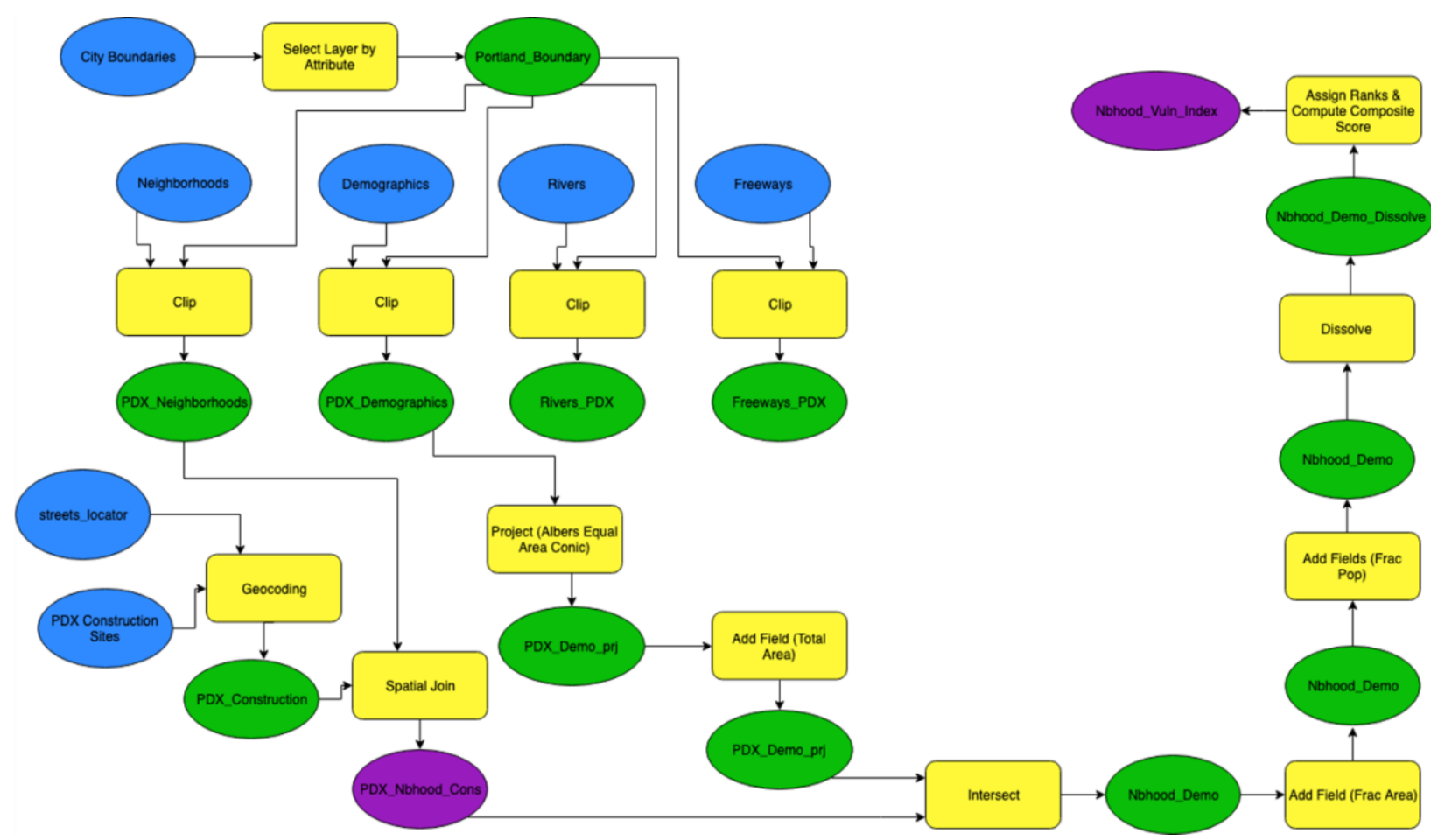

Figure B2. This figure shows the steps taken to perform the spatial analysis done in ESRI ArcGIS for this exploratory analysis. 
Appendix C. “The Issue” webpage contents

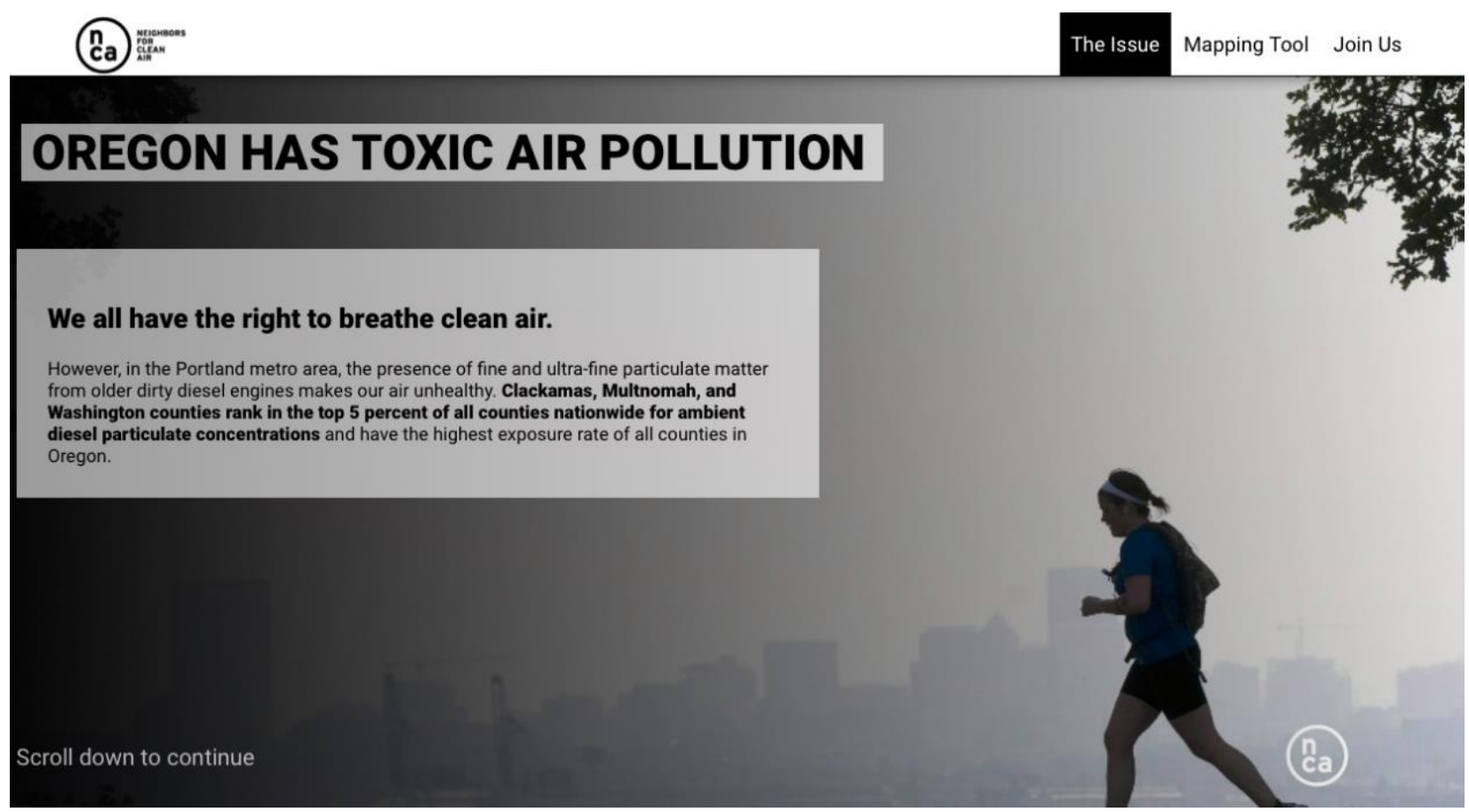

\section{(马)}

\section{DIESEL ENGINES ARE A PRIMARY SOURCE OF POLLUTION}

While there are many sources for air pollution in Oregon - industry, automobiles, burning wood at homes, wildfires - one of the most significant and underregulated sources is diesel.

Areas with higher diesel vehicle traffic, like near freight corridors, rail yards, or construction sites, have levels of diesel pollution over 10

times Oregon health standards for healthy air.
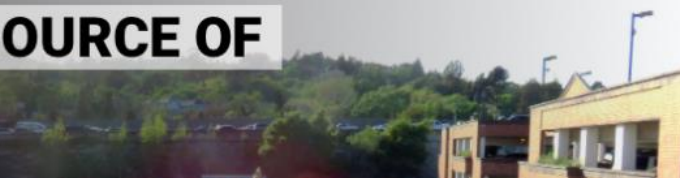
(19)

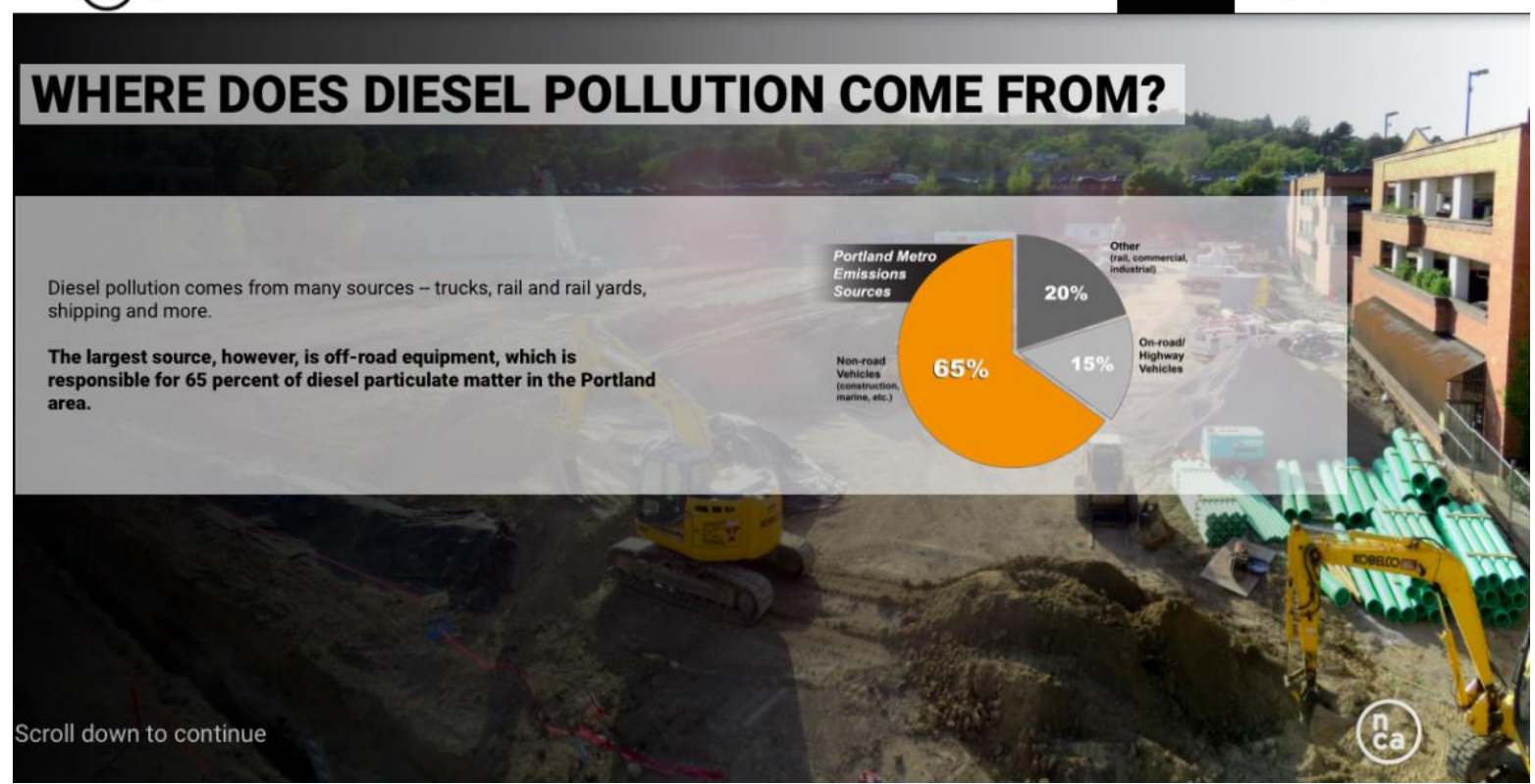

(19.)

The Issue Mapping Tool Join Us

\section{WHAT IS OFF-ROAD EQUIPMENT?}

Off-road equipment is what we call the heavy construction vehicles such as excavators, wheel loaders, articulated and rigid dump trucks moving in and out of all of our neighborhoods. The term also applies to logging and agricultural equipment.

In Oregon, these vehicles are not required to meet diesel exhaust standards. 

(na)

\section{OLD DIESEL ENGINES ARE DANGEROUS}

One component of the dangerous particles produced by diesel is black carbon, which not only harms human health but is a significant contributor to climate change.

Older diesel engines can emit $85 \%$ more black carbon than newer engines. While legislation is in place to begin to replace older diese trucks, no requirements exist to replace older rail and construction equipment.

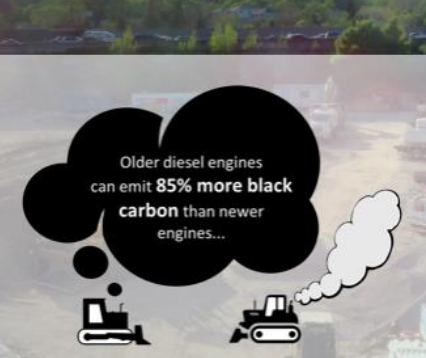

Scroll down to continue

$$
\text { (19.) }
$$

\section{DIESEL ENGINES ENDANGER OUR HEALTH}

Diesel engines emit fine particulate matter, tiny particles that work deeply into our lungs and enter our blood stream. This matter,

sometimes called PM2.5 or PM10, can damage our lungs and create a number of health issues.

These health issues include cancer, increase the risk of heart attack, stroke and cardiovascular disease, and can cause adverse nervous system impacts. Diesel can exacerbate asthma, and can lead to lowweight and preterm births. Individuals living in areas with bad air pollution also have a significantly higher risk of mortality from COVID 19.

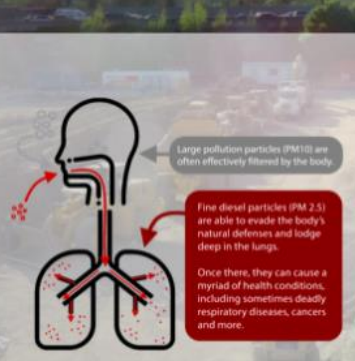


(a)

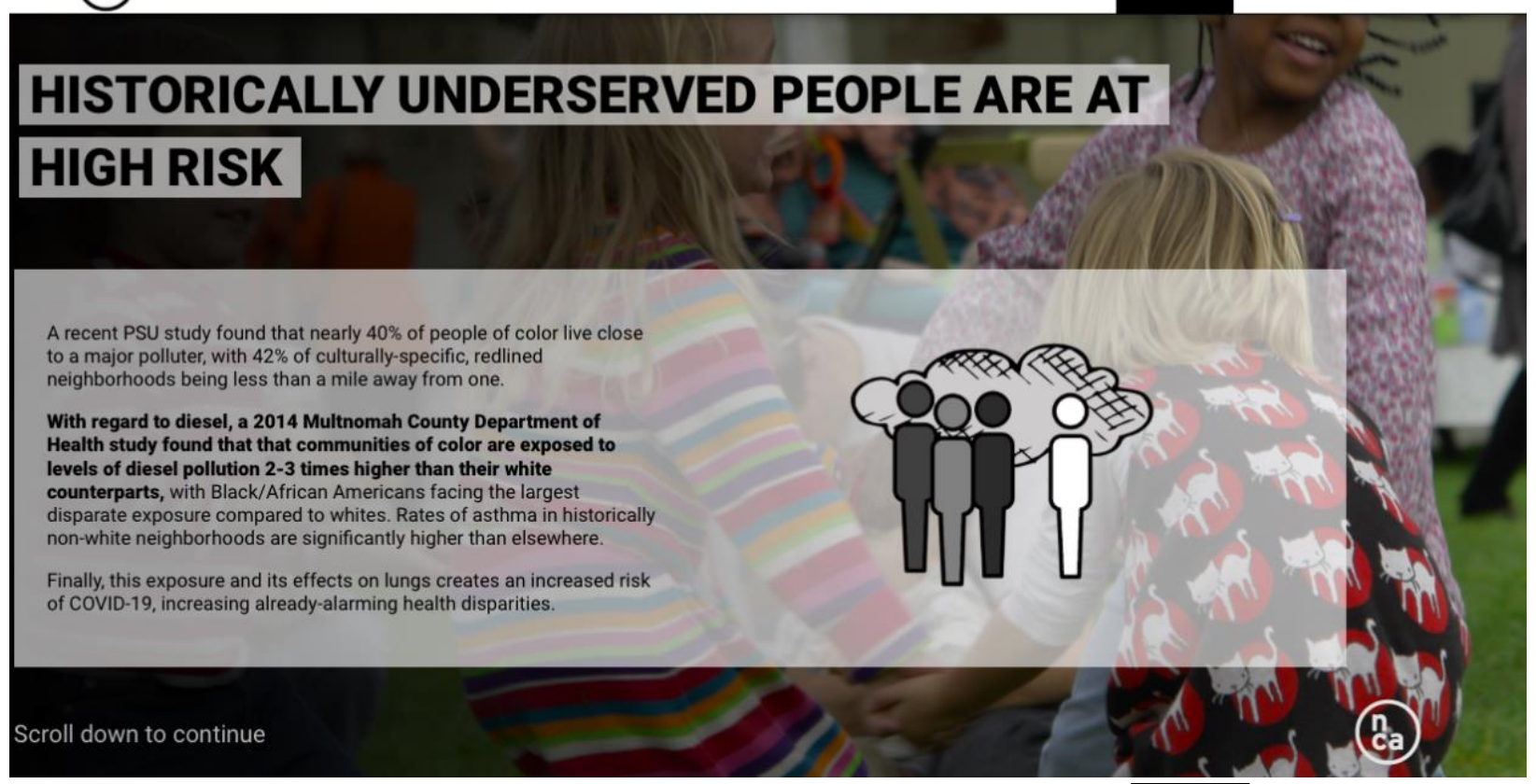

(19)

\section{WOMEN, CHILDREN AND THE ELDERLY ARE ESPECIALLY VULNERABLE}

Studies have shown that women exposed to high levels of air pollution in their third trimester were twice as likely to deliver children with autism.

Children are effected by air pollution more than adults because their lungs are still in the developmental phase and they breathe, on average, 50 percent more air per pound of body weight than adults do. Also, increasing evidence shows that air pollution affects a child's brain development, lowering test scores and increasing of ADHD, ADD as well as impulse control.

Research into the effects of air pollution among the elderly suggests that it can raise the risk of strokes, Parkinson's disease, and Alzheimer's disease.

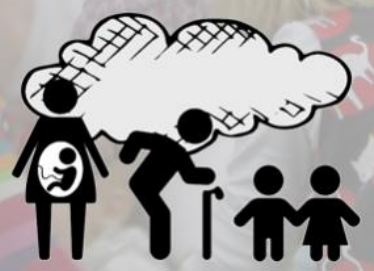


(1)

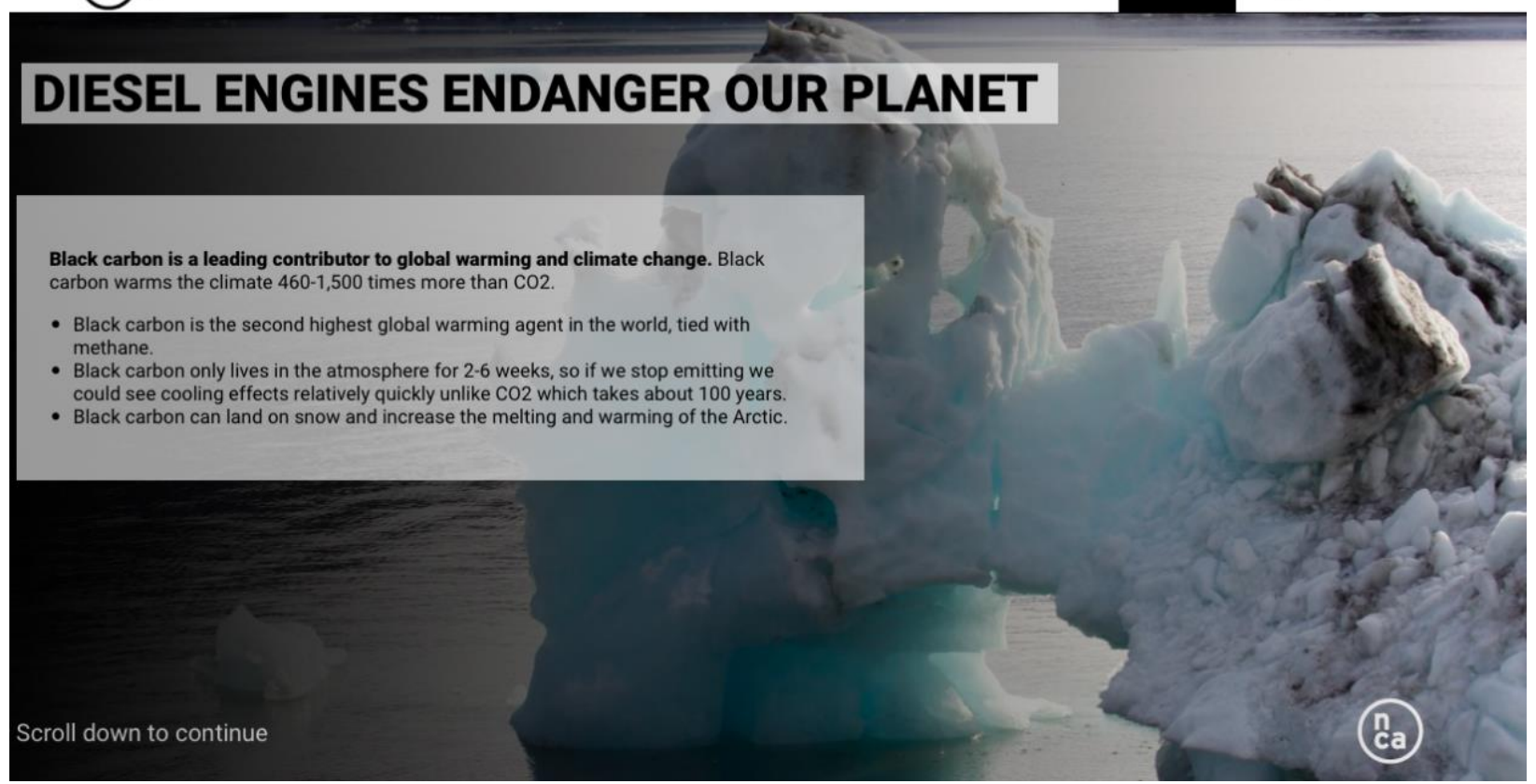

(19a)

The Issue Mapping Tool Join Us

\section{WE NEED A STATEWIDE CLEAN STANDARD}

V About these images

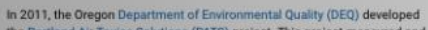

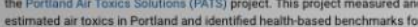

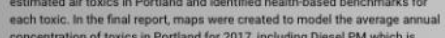

concentration of toxics in Portland for 2017 . Including Diesel PM which is

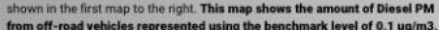

Using the sidide, you can see the estimated docresese in overal Ditesel PM.

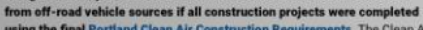

Construction Ropiviroments are currently veluntary and have only been.

asdopted by a tew public agencies By 2026, the requirements state that

construction equipment on site must be Tier 4 (the cleanest wailable) or have

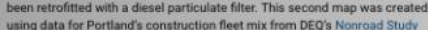

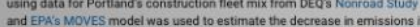
al equipment was Tier 4

\section{Diesel Particulate Matter from Off-road Sources}

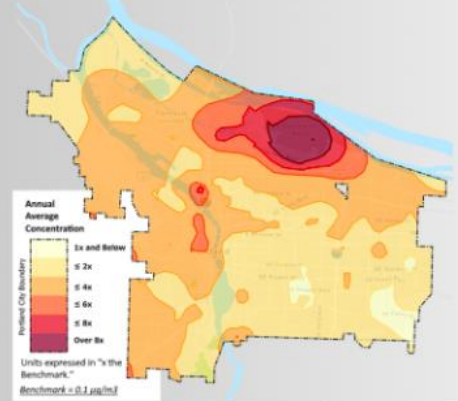

Source: whatsinourair.org 


\section{Appendix D: Portland SE Lafayette Monitoring Station Data}

Table D1. Annual average concentrations from Oregon DEQ Monitoring Station. Station Name: Portland SE Lafayette, Type: Average, Timebase: 60 Minute Timebase, Period: 8/28/2020 23:30 - 8/14/2020 01:00

\begin{tabular}{|c|c|c|c|c|c|c|c|}
\hline Type & $\begin{array}{c}\text { Temperature } \\
\mathrm{C}^{\circ}\end{array}$ & $\begin{array}{c}\text { Aethalometer } \\
\text { ug/m3(S) }\end{array}$ & $\begin{array}{c}\text { Carbon } \\
\text { Monoxide } \\
\text { ppb }\end{array}$ & $\begin{array}{c}\text { Nitrogen } \\
\text { Dioxide } \\
\text { ppb }\end{array}$ & $\begin{array}{c}\text { Oxides of } \\
\text { Nitrogen } \\
\text { ppb }\end{array}$ & $\begin{array}{c}\text { Ozone } \\
\text { ppb }\end{array}$ & $\begin{array}{c}\text { PM2.5 } \\
\text { ug/m3(L) }\end{array}$ \\
\hline Avg & 22 & 0.353 & 174.4 & 4.3 & 5.4 & 24 & 5.5 \\
\hline \multicolumn{8}{|l|}{ Data } \\
\hline Percent & 99.2 & 99.7 & 98.3 & 99.2 & 99.2 & 100 & 100 \\
\hline Maximum & 39.5 & 2.428 & 574.5 & 24 & 25.7 & 77 & 22.5 \\
\hline Minimum & 11 & 0.051 & -38 & 0.9 & 1.4 & 1 & 1.6 \\
\hline Name & $\begin{array}{c}\text { Ambient } \\
\text { Temperature }\end{array}$ & $\begin{array}{l}\text { Black Carbon } \\
\text { BC6 } 880 \mathrm{~nm}\end{array}$ & $\begin{array}{l}\text { Carbon } \\
\text { Monoxide }\end{array}$ & $\begin{array}{l}\text { Nitrogen } \\
\text { Dioxide }\end{array}$ & $\begin{array}{l}\text { Oxides of } \\
\text { Nitrogen }\end{array}$ & Ozone & PM2.5 Est \\
\hline Num & 356 & 358 & 353 & 356 & 356 & 359 & 359 \\
\hline STD & 6.1 & 0.3 & 64.3 & 3.2 & 4.0 & 14.9 & 3.1 \\
\hline Max Date & $8 / 16 / 2020$ & $8 / 16 / 2020$ & $8 / 16 / 2020$ & $8 / 16 / 2020$ & $8 / 16 / 2020$ & $8 / 15 / 2020$ & $8 / 16 / 2020$ \\
\hline $\begin{array}{c}\text { Max } \\
\text { Value } \\
\text { Time }\end{array}$ & $13: 00$ & $21: 00$ & $22: 00$ & 21:00 & 21:00 & $17: 00$ & 21:00 \\
\hline Min Date & $8 / 27 / 2020$ & $8 / 21 / 2020$ & $8 / 14 / 2020$ & $8 / 20 / 2020$ & $8 / 16 / 2020$ & $8 / 22 / 2020$ & $8 / 21 / 2020$ \\
\hline Min Time & 06:00 & 04:00 & $14: 00$ & $11: 00$ & $14: 00$ & 05:00 & 05:00 \\
\hline
\end{tabular}




\section{Appendix E: Citizen Science Tool Framework}

The citizen science tool could be designed by finding the average horsepower of each of the nine equipment types that are responsible for $70 \%$ of construction site emissions. These are:

backhoes, bulldozers, excavators, generators, motor graders, off-road trucks, rubber tire loaders, track loaders, and skid-steer loaders (Rasdorf et. al., 2010). Then once you find an average horsepower for each equipment, you can find the associated emission standards in the tables below for each engine tier level (1-4). If a sticker program was implemented, this would allow users of the tool to be able to select the type of equipment they saw (with photo references) and the engine tier. This information would allow the tool to find the associated emission standard associated to multiply it by number of hours the equipment is operated on a daily or weekly basis.

Table E1. This table is the Tier 1-3 Emission Standards by horsepower and tier of engines for off-road diesel engines set by the EPA, g/kWh $(\mathrm{g} / \mathrm{bhp} \cdot \mathrm{hr}$ ). Tier 4 (newest technology) standards are listed in Table E2. (Source: DieselNet, 2020; EPA, 2016).

\begin{tabular}{|c|c|c|c|c|c|c|c|}
\hline Engine Power & Tier & Year & $\mathrm{CO}$ & $\mathrm{HC}$ & $\mathbf{N M H C}+\mathbf{N O x}$ & NOx & PM \\
\hline \multirow{2}{*}{$\begin{array}{l}\mathrm{kW}<8 \\
(\mathrm{hp}<11)\end{array}$} & Tier 1 & 2000 & $8.0(6.0)$ & - & $10.5(7.8)$ & - & $1.0(0.75)$ \\
\hline & Tier 2 & 2005 & $8.0(6.0)$ & - & $7.5(5.6)$ & - & $0.8(0.6)$ \\
\hline \multirow{2}{*}{$\begin{array}{l}8 \leq \mathrm{kW}<19 \\
(11 \leq \mathrm{hp}<25)\end{array}$} & Tier 1 & 2000 & $6.6(4.9)$ & - & $9.5(7.1)$ & - & $0.8(0.6)$ \\
\hline & Tier 2 & 2005 & $6.6(4.9)$ & - & $7.5(5.6)$ & - & $0.8(0.6)$ \\
\hline \multirow{2}{*}{$\begin{array}{l}19 \leq \mathrm{kW}<37 \\
(25 \leq \mathrm{hp}<50)\end{array}$} & Tier 1 & 1999 & $5.5(4.1)$ & - & $9.5(7.1)$ & - & $0.8(0.6)$ \\
\hline & Tier 2 & 2004 & $5.5(4.1)$ & - & $7.5(5.6)$ & - & $0.6(0.45)$ \\
\hline \multirow{4}{*}{$\begin{array}{l}37 \leq \mathrm{kW}<75 \\
(50 \leq \mathrm{hp}<100)\end{array}$} & Tier 1 & 1998 & - & - & - & $9.2(6.9)$ & - \\
\hline & Tier 2 & 2004 & $5.0(3.7)$ & - & $7.5(5.6)$ & - & $0.4(0.3)$ \\
\hline & Tier 3 & 2008 & $5.0(3.7)$ & - & $4.7(3.5)$ & - & $-\dagger$ \\
\hline & Tier 1 & 1997 & - & - & - & $9.2(6.9)$ & - \\
\hline
\end{tabular}




\begin{tabular}{|c|c|c|c|c|c|c|c|}
\hline Engine Power & Tier & Year & CO & $\mathrm{HC}$ & $\mathrm{NMHC}+\mathrm{NOx}$ & NOx & PM \\
\hline \multirow{2}{*}{$\begin{array}{l}75 \leq \mathrm{kW}<130 \\
(100 \leq \mathrm{hp}<175)\end{array}$} & Tier 2 & 2003 & $5.0(3.7)$ & - & $6.6(4.9)$ & - & $0.3(0.22)$ \\
\hline & Tier 3 & 2007 & $5.0(3.7)$ & - & $4.0(3.0)$ & - & $-\dagger$ \\
\hline \multirow{3}{*}{$\begin{array}{l}130 \leq \mathrm{kW}<225 \\
(175 \leq \mathrm{hp}<300)\end{array}$} & Tier 1 & 1996 & $11.4(8.5)$ & $1.3(1.0)$ & - & $9.2(6.9)$ & $0.54(0.4)$ \\
\hline & Tier 2 & 2003 & $3.5(2.6)$ & - & $6.6(4.9)$ & - & $0.2(0.15)$ \\
\hline & Tier 3 & 2006 & $3.5(2.6)$ & - & $4.0(3.0)$ & - & $-\dagger$ \\
\hline \multirow{3}{*}{$\begin{array}{l}225 \leq \mathrm{kW}<450 \\
(300 \leq \mathrm{hp}<600)\end{array}$} & Tier 1 & 1996 & $11.4(8.5)$ & $1.3(1.0)$ & - & $9.2(6.9)$ & $0.54(0.4)$ \\
\hline & Tier 2 & 2001 & $3.5(2.6)$ & - & $6.4(4.8)$ & - & $0.2(0.15)$ \\
\hline & Tier 3 & 2006 & $3.5(2.6)$ & - & $4.0(3.0)$ & - & $-\dagger$ \\
\hline \multirow{3}{*}{$\begin{array}{l}450 \leq \mathrm{kW}<560 \\
(600 \leq \mathrm{hp}<750)\end{array}$} & Tier 1 & 1996 & $11.4(8.5)$ & $1.3(1.0)$ & - & $9.2(6.9)$ & $0.54(0.4)$ \\
\hline & Tier 2 & 2002 & $3.5(2.6)$ & - & $6.4(4.8)$ & - & $0.2(0.15)$ \\
\hline & Tier 3 & 2006 & $3.5(2.6)$ & - & $4.0(3.0)$ & - & $-\dagger$ \\
\hline \multirow{2}{*}{$\begin{array}{l}\mathrm{kW} \geq 560 \\
(\mathrm{hp} \geq 750)\end{array}$} & Tier 1 & 2000 & $11.4(8.5)$ & $1.3(1.0)$ & - & $9.2(6.9)$ & $0.54(0.4)$ \\
\hline & Tier 2 & 2006 & $3.5(2.6)$ & - & $6.4(4.8)$ & - & $0.2(0.15)$ \\
\hline \multicolumn{8}{|c|}{$\dagger$ Not adopted, engines must meet Tier 2 PM standard. } \\
\hline
\end{tabular}

Table E2. This table is the Tier 4 Emission Standards by horsepower and tier of engines for offroad diesel engines, $\mathrm{g} / \mathrm{kWh}(\mathrm{g} / \mathrm{bhp} \cdot \mathrm{hr})$. This is the newest tier of engine standards set by the EPA. (Source: DieselNet, 2020; EPA, 2016). 


\begin{tabular}{|c|c|c|c|c|c|c|}
\hline Engine Power & Year & $\mathrm{CO}$ & NMHC & $\mathbf{N M H C}+\mathbf{N O}_{\mathbf{x}}$ & $\mathrm{NO}_{\mathrm{x}}$ & PM \\
\hline $\begin{array}{l}\mathrm{kW}<8 \\
(\mathrm{hp}<11)\end{array}$ & 2008 & $\begin{array}{c}8.0 \\
(6.0)\end{array}$ & - & $7.5(5.6)$ & - & $0.4^{\mathrm{a}}(0.3)$ \\
\hline $\begin{array}{l}8 \leq \mathrm{kW}<19 \\
(11 \leq \mathrm{hp}<25)\end{array}$ & 2008 & $\begin{array}{c}6.6 \\
(4.9)\end{array}$ & - & $7.5(5.6)$ & - & $0.4(0.3)$ \\
\hline \multirow[t]{2}{*}{$\begin{array}{l}19 \leq \mathrm{kW}<37 \\
(25 \leq \mathrm{hp}<50)\end{array}$} & 2008 & $\begin{array}{c}5.5 \\
(4.1)\end{array}$ & - & $7.5(5.6)$ & - & $0.3(0.22)$ \\
\hline & 2013 & $\begin{array}{c}5.5 \\
(4.1)\end{array}$ & - & $4.7(3.5)$ & - & $\begin{array}{c}0.03 \\
(0.022)\end{array}$ \\
\hline \multirow[t]{2}{*}{$\begin{array}{l}37 \leq \mathrm{kW}<56 \\
(50 \leq \mathrm{hp}<75)\end{array}$} & 2008 & $\begin{array}{c}5.0 \\
(3.7)\end{array}$ & - & $4.7(3.5)$ & - & $0.3^{b}(0.22)$ \\
\hline & 2013 & $\begin{array}{c}5.0 \\
(3.7)\end{array}$ & - & $4.7(3.5)$ & - & $\begin{array}{c}0.03 \\
(0.022)\end{array}$ \\
\hline $\begin{array}{l}56 \leq \mathrm{kW}<130 \\
(75 \leq \mathrm{hp}<175)\end{array}$ & $\begin{array}{l}2012- \\
2014^{\mathrm{c}}\end{array}$ & $\begin{array}{c}5.0 \\
(3.7)\end{array}$ & $\begin{array}{c}0.19 \\
(0.14)\end{array}$ & - & $\begin{array}{c}0.40 \\
(0.30)\end{array}$ & $\begin{array}{c}0.02 \\
(0.015)\end{array}$ \\
\hline $\begin{array}{l}130 \leq \mathrm{kW} \leq 560 \\
(175 \leq \mathrm{hp} \leq 750)\end{array}$ & $\begin{array}{l}2011^{-} \\
2014^{d}\end{array}$ & $\begin{array}{l}3.5 \\
(2.6)\end{array}$ & $\begin{array}{c}0.19 \\
(0.14)\end{array}$ & - & $\begin{array}{c}0.40 \\
(0.30)\end{array}$ & $\begin{array}{c}0.02 \\
(0.015)\end{array}$ \\
\hline
\end{tabular}

